ARTICLE

https://doi.org/10.1038/s41467-019-13685-2

\title{
Platinum-copper single atom alloy catalysts with high performance towards glycerol hydrogenolysis
}

Xi Zhang ${ }^{1,4}$, Guoqing Cui (i] ${ }^{1,4}$, Haisong Feng ${ }^{1}$, Lifang Chen ${ }^{1}$, Hui Wang ${ }^{1}$, Bin Wang ${ }^{2}$, Xin Zhang ${ }^{1 \star}$, Lirong Zheng ${ }^{3 \star}$, Song Hong (1) ${ }^{1 \star} \&$ Min Wei (1) ${ }^{1 \star}$

Selective hydrogenolysis of biomass-derived glycerol to propanediol is an important reaction to produce high value-added chemicals but remains a big challenge. Herein we report a PtCu single atom alloy (SAA) catalyst with single Pt atom dispersed on $\mathrm{Cu}$ nanoclusters, which exhibits dramatically boosted catalytic performance (yield: 98.8\%) towards glycerol hydrogenolysis to 1,2-propanediol. Remarkably, the turnover frequency reaches up to $2.6 \times 10^{3}$ mol $_{\text {glycerol }} \cdot$ molptCu-SAA $^{-1} \cdot \mathrm{h}^{-1}$, which is to our knowledge the largest value among reported heterogeneous metal catalysts. Both in situ experimental studies and theoretical calculations verify interface sites of PtCu-SAA serve as intrinsic active sites, in which the single Pt atom facilitates the breakage of central $\mathrm{C}-\mathrm{H}$ bond whilst the terminal $\mathrm{C}-\mathrm{O}$ bond undergoes dissociation adsorption on adjacent $\mathrm{Cu}$ atom. This interfacial synergistic catalysis based on PtCu-SAA changes the reaction pathway with a decreased activation energy, which can be extended to other noble metal alloy systems.

\footnotetext{
${ }^{1}$ State Key Laboratory of Chemical Resource Engineering, Beijing Advanced Innovation Center for Soft Matter Science and Engineering, Beijing University of Chemical Technology, 100029 Beijing, P. R. China. ${ }^{2}$ Beijing Research Institute of Chemical Industry, Sinopec Group, 100013 Beijing, P. R. China. ${ }^{3}$ Institute of High Energy Physics, Chinese Academy of Sciences, 100049 Beijing, P. R. China. ${ }^{4}$ These authors contribute equally: Xi Zhang, Guoqing Cui.

*email: zhangxin@mail.buct.edu.cn; zhengIr@ihep.ac.cn; hongsong@mail.buct.edu.cn; weimin@mail.buct.edu.cn
} 
W ith the huge consumption of limited reserves fossil fuels and increasing environmental issues, biomass, as the abundant carbon-neutral renewable resources, has attracted considerable attention in both fundamental study and industrial application. In this context, converting biomass-derived feedstocks (e.g., polyols, sugars) to clean fuels and fine chemicals through green catalytic processes has become a promising strategy $^{1}$. In particular, glycerol is usually regarded as an important biomass-derived "platform" chemical, since it is the smallest and most representative polyol with a highly functionalized molecule ${ }^{2,3}$. Among various transformations approaches (e.g., hydrogenolysis, oxidation, and dehydration etc.), one of the most favorable processes is the highly selective of hydrogenolysis glycerol to 1,2-propanediol (1,2-PDO), which serves as a significant commodity chemical widely applied in the production of unsaturated polyester resin, deicing agent and cosmetics ${ }^{4,5}$. Normally, hydrogenolysis reaction undergoes splitting of $\mathrm{C}-\mathrm{O}$ and/or $\mathrm{C}-\mathrm{C}$ bonds and simultaneous addition of hydrogen to form a desired product $^{6,7}$. Especially, selective breakage of one terminal $\mathrm{C}-\mathrm{O}$ bond with the preservation of other $\mathrm{C}-\mathrm{O}$ and $\mathrm{C}-\mathrm{C}$ bond is highly crucial to produce 1,2-PDO, due to the coexistence of multiple hydroxyl groups and $\mathrm{C}-\mathrm{C}$ bonds ${ }^{8-10}$. Along this line, considerable effort has been focused on exploration of heterogeneous catalysts towards this hydrogenolysis reaction, including nonnoble metals (e.g., $\mathrm{Co}, \mathrm{Ni}$, and $\mathrm{Cu}$ ), noble metals (e.g., $\mathrm{Pd}, \mathrm{Ru}$, and $\mathrm{Pt}$ ), and bimetallic (e.g., $\mathrm{RuFe}, \mathrm{CuNi}$, and $\mathrm{CuPd}$ ) catalysts ${ }^{10-14}$. Although much progress has been made, structure design and development of highly efficient catalysts to acquire high activity, selectivity and stability simultaneously, still remain a big challenge.

Generally, bimetallic alloy catalysts have shown great advantages in boosting catalytic performance in many reactions, compared with monometallic catalysts, due to their synergistic effect $^{15-17}$. To maximize the utilization of predominant metal atom (especially noble metal), one of the extreme cases is to atomically disperse one active metal on the surface of the second one (e.g., single atom alloy, SAA $)^{18-21}$. SAA catalysts has been proven to possess peculiar electronic and geometric features rather different from their constituent metals, which provide unique active centers and consequently change the reaction pathway ${ }^{22-24}$. So far SAA exhibits remarkable catalytic behavior in many chemical reactions (e.g., hydrogenation, hydrogenolysis) ${ }^{25-30}$. Currently, selective glycerol hydrogenolysis to $1,2-\mathrm{PDO}$ is mainly performed over $\mathrm{Cu}$-based catalysts, because of their strong tendency in cleaving the $\mathrm{C}-\mathrm{O}$ bond and low scission ability for $\mathrm{C}-\mathrm{C}$ bond, whereas suffers from an unsatisfactory activity and poor thermal stability 31,32 . In contrast, noble Pt-based catalysts exhibit superior activity but are prone to break $\mathrm{C}-\mathrm{C}$ bond, resulting in a loss of selectivity ${ }^{33,34}$. Inspired by the above facts, if a unique bimetallic SAA catalyst is designed by distributing Pt atoms onto $\mathrm{Cu}$ nanoparticles to marry their advantages, both activity and selectivity would be guaranteed simultaneously.

Herein, we design and synthesize a $\mathrm{PtCu}$ single atom alloy (PtCu-SAA) catalyst based on structural transformation from hydrotalcite precursor (CuMgAl-LDH) followed by a galvanic replacement reaction to introduce $\mathrm{Pt}$ single atom onto the surface of $\mathrm{Cu}$ nanoclusters. A series of elaborate characterizations including AC-HAADF-STEM, in situ CO-DRIFTS and in situ EXAFS confirm the formation of SAA, where a few $\mathrm{Pt}$ atoms are absolutely isolated by $\mathrm{Cu}$ atoms. The $\mathrm{PtCu}-\mathrm{SAA}$ exhibits extraordinary catalytic performance towards glycerol hydrogenolysis to 1,2-propanediol (conversion: $99.6 \%$; selectivity: $99.2 \%$ ), under mild reaction conditions $\left(200{ }^{\circ} \mathrm{C}, 2 \mathrm{MPa}\right)$. Most notably, the turnover frequency (TOF) value of $\mathrm{PtCu}-\mathrm{SAA}$ reaches up to

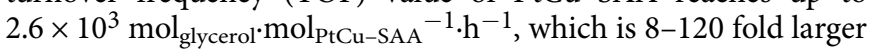
than that of metal catalysts ever reported. This is to our knowledge the highest reactivity among heterogeneous catalysts under identical reaction conditions. Furthermore, both in situ experimental studies and theoretical calculations substantiate that the $\mathrm{Pt}-\mathrm{Cu}$ interface sites serve as intrinsic active centers: the single Pt atom facilitates the activation adsorption of central $\mathrm{C}-\mathrm{H}$ bond in glycerol molecule, while the terminal $\mathrm{C}-\mathrm{O}$ bond undergoes dissociation adsorption on adjacent $\mathrm{Cu}$ atoms. Consequently, this interfacial synergistic catalysis changes the reaction pathway with a lower activation energy, compared with traditional monometallic catalysts. Therefore, this work illustrates a successful paradigm for the design of SAA catalyst towards boosting polyols hydrogenolysis reaction, which shows potential application in biomass feedstocks to clean fuels and fine chemicals.

\section{Results}

Structural characterizations. The XRD patterns of CuMgAl-LDH precursors in Fig. 1a show series of characteristic reflections at $2 \theta 11.9^{\circ}, 23.5^{\circ}$, and $34.9^{\circ}$, indexed to the (003), (006), and (012) of a typical carbonate-containing LDH phase, respectively ${ }^{35}$. The subsequent calcination treatment (air, $500{ }^{\circ} \mathrm{C}$ ) results in a structural topotactic transformation from hydrotalcite to mixed metal oxides (CuMgAl-MMO). The XRD patterns display two weak peaks $\left(35.5^{\circ}, 38.7^{\circ}\right)$ attributed to the (111) reflection of $\mathrm{CuO}$ (JCPDS 048-1548), and other two strong peaks $\left(42.9^{\circ}, 62.3^{\circ}\right)$ indexed to high-crystallinity $\mathrm{MgO}$ (JCPDS 045-0946). No reflection of $\mathrm{Al}_{2} \mathrm{O}_{3}$ was observed, implying an amorphous phase ${ }^{36}$. Afterwards, samples of CuMgAl-MMO were carefully reduced in a $\mathrm{H}_{2} / \mathrm{Ar}$ atmosphere to obtain $\mathrm{Cu}$ nanoclusters supported on oxides matrix ( $\mathrm{Cu} / \mathrm{MMO})$. Finally, $\mathrm{PtCu}-\mathrm{SAA}$ sample was obtained by a galvanic replacement reaction to introduce platinum single atom onto the surface of $\mathrm{Cu}$ NPs (Fig. 1b). Meanwhile, the $\mathrm{Pt}-\mathrm{Cu}$ alloy samples with various atomic ratios were synthesized as control samples (PtCu-NPs). It is noted that $\mathrm{Cu} / \mathrm{MMO}$ and $\mathrm{PtCu}-\mathrm{SAA}$ show rather identical $\mathrm{XRD}$ patterns without $\mathrm{Cu}$ or $\mathrm{CuO}$ phase, implying a high dispersion degree of copper species. Additionally, PtCu-SAA and $\mathrm{PtCu}-\mathrm{NP}-1$ sample (Supplementary Fig. 1a) do not display $\mathrm{Pt}$ reflection while the $\mathrm{PtCu}-\mathrm{NP}-2$ sample shows three weak peaks at $2 \theta 39.8^{\circ}, 46.3^{\circ}$, and $81.3^{\circ}$ indexed to the (111), (200), and (311) reflection of $\mathrm{Pt}$ (JCPDS 087-0646), due to the increase of $\mathrm{Pt}$ loading.

HRTEM measurements were carried out to gain more spatially-resolved structure information on the $\mathrm{Cu} / \mathrm{MMO}$ and PtCu-SAA samples. From the HRTEM images of both samples (Fig. 2a, b and Supplementary Fig. 2a, c), Cu NPs are well dispersed and embedded onto the MMO support with a similar content $(\sim 3.2 \mathrm{wt} . \%)$ and a close particle size $(\sim 2.7 \mathrm{~nm})$. Moreover, two clear crystalline phases are identified for these two samples: $\mathrm{Cu}$ (111) plane (lattice spacing: $0.209 \mathrm{~nm}$ ) and $\mathrm{MgO}$ (200) plane (lattice fringe: $0.210 \mathrm{~nm}$ ), respectively. To unambiguously observe the Pt species, the aberration-correction high-angle annular dark-field scanning transmission electron microscopy (AC-HAADF-STEM) imaging technique was employed to distinguish $\mathrm{Pt}$ atom based on the difference in $\mathrm{Z}$-contrast. The image of $\mathrm{Pt} / \mathrm{MMO}$ samples displays both $\mathrm{Pt}$ nanoclusters and $\mathrm{Pt}$ single atoms (Supplementary Fig. 2b, d). In contrast, a number of bright and atom-sized features (Fig. 2c) attributed to individual $\mathrm{Pt}$ atoms can be discerned on the crystal surface of $\mathrm{Cu}$ in $\mathrm{PtCu}-\mathrm{SAA}$ samples. Interestingly, these isolated $\mathrm{Pt}$ atoms are surrounded by $\mathrm{Cu}$ atoms in several different regions of the samples, rather than Pt nanoclusters (Supplementary Fig. 3). A typical AC-HAADF-STEM image of an individual $\mathrm{Cu}$ nanoclusters in Fig. $2 \mathrm{~d}$ was displayed to highlight the surface $\mathrm{Pt}$ atoms. The randomly enlarged image further confirms the substitution of 
a

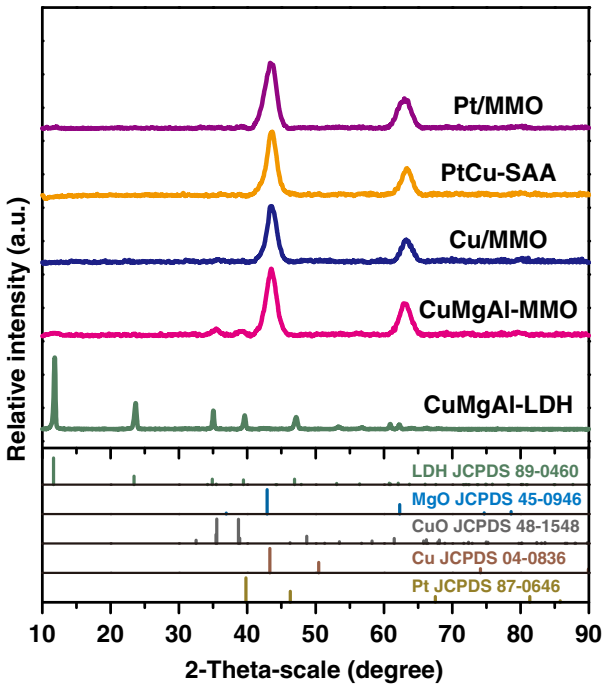

b

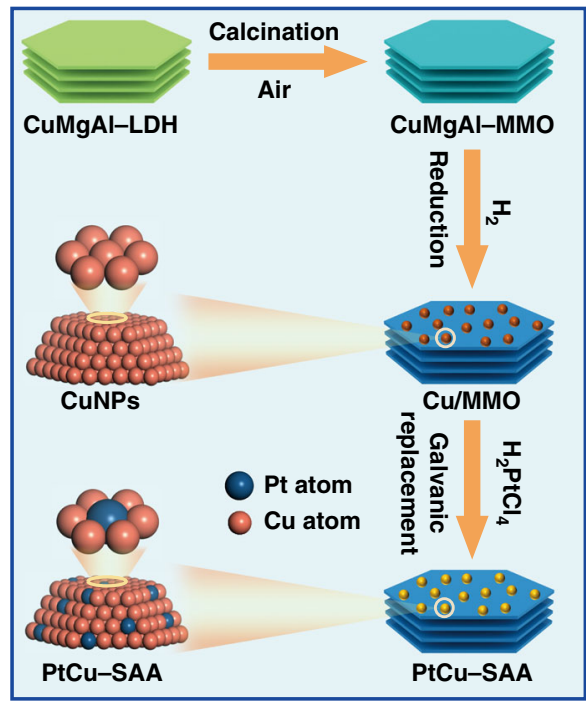

Fig. 1 Synthesis and characterization of PtCu-SAA from LDHs precursor. a In situ XRD patterns of various samples; $\mathbf{b}$ a schematic illustration for the preparation of PtCu-SAA.
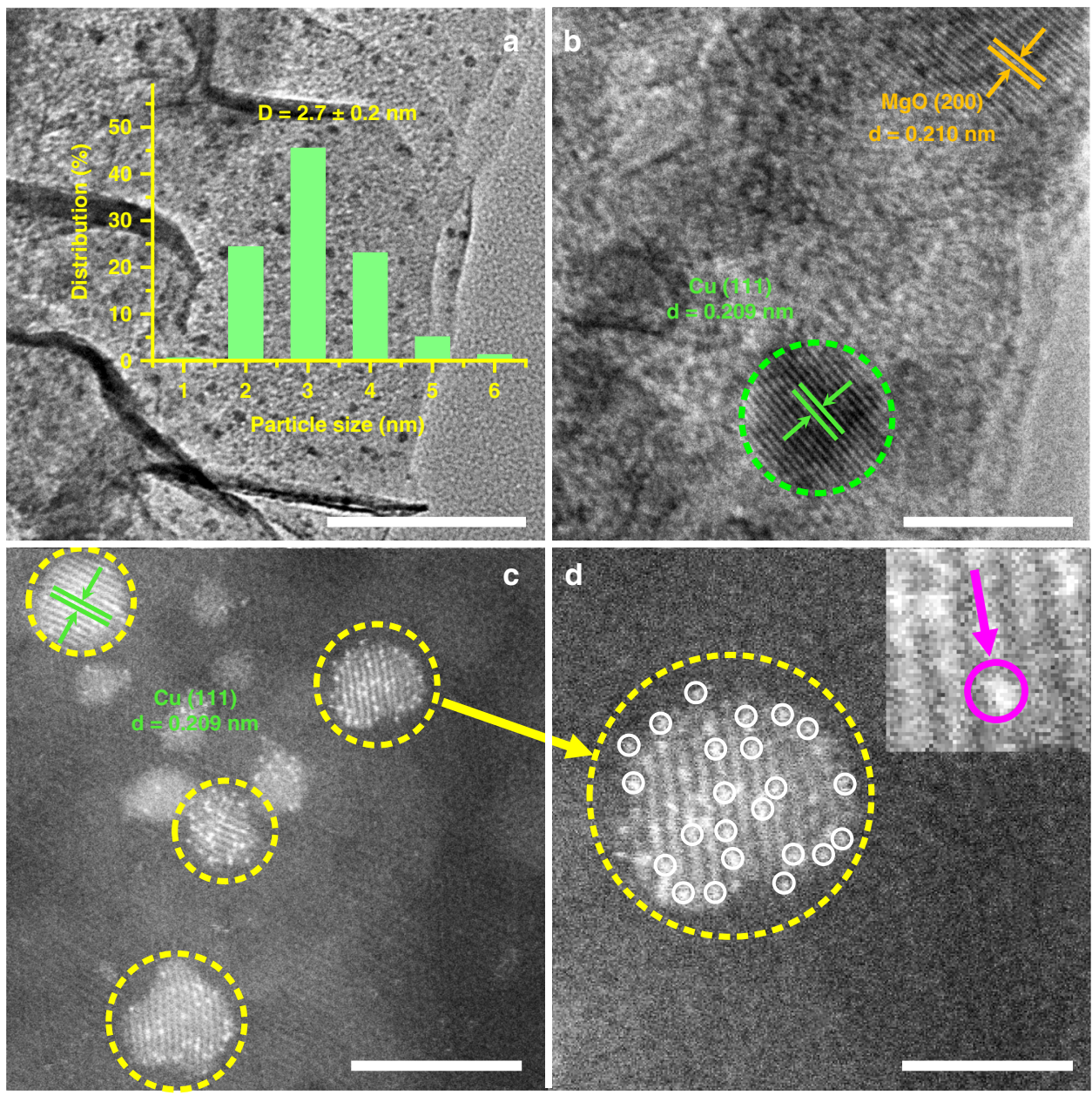

Fig. 2 Identification of PtCu single atom alloy. a TEM image, b HRTEM image, $\mathbf{c}$ AC-HAADF-STEM image of PtCu-SAA, and $\mathbf{d}$ corresponding enlarged images. Scale bars: a $100 \mathrm{~nm}$; b $5 \mathrm{~nm}$; c, and $\mathbf{d} 2 \mathrm{~nm}$. 
surface $\mathrm{Cu}$ atoms by isolated $\mathrm{Pt}$ atom, where the single $\mathrm{Pt}$ atom was clearly observed (marked by magenta circle and arrow). The lattice spacing of PtCu-SAA in Fig. $2 \mathrm{c}$ is $0.209 \mathrm{~nm}$, in good agreement with that of pure $\mathrm{Cu}(111)$ in $\mathrm{Cu} / \mathrm{MMO}$ sample. In contrast, three crystalline phases of $\mathrm{PtCu}-\mathrm{NPs}$ sample are identified for $\mathrm{PtCu}$ alloy (Supplementary Fig. 1b-c): $\mathrm{Cu}$ (111) plane (expanded lattice spacing: $0.211 \mathrm{~nm}$ ), Pt (111) and (200) plane (shrunk lattice fringe: $0.220 \mathrm{~nm}$ and $0.190 \mathrm{~nm}$ ), respectively ${ }^{37}$. In addition, the energy dispersive spectroscopy (EDS) mapping images of PtCu-SAA samples (Supplementary Fig. 4) display $\mathrm{Pt}$ is mainly distributed on the surface of $\mathrm{Cu}$ nanoclusters and not supported on $\mathrm{MgAl}-\mathrm{MMO}$ substrate. Moreover, the $\mathrm{Cu}$ dispersion $\left(\mathrm{D}_{\mathrm{Cu}}\right)$ of $\mathrm{PtCu}-\mathrm{SAA}$ sample determined by classic $\mathrm{N}_{2} \mathrm{O}$ chemisorption, is significantly up to $50.7 \%$ (Table 1), similar to that of $\mathrm{Cu} / \mathrm{MMO}$ (52.3\%). The $\mathrm{Cu} / \mathrm{MMO}$ and PtCu-SAA samples display similar reduction degree of $\mathrm{Cu}(\sim 90 \%)$ within the range of reduction temperature (Table 1 ), indicating predominant $\mathrm{Cu}^{0}$ species accompanied with a little $\mathrm{Cu}^{+}$species.

In situ CO-DRIFTS measurements were performed to probe the atomic geometry configuration of Pt ensembles on the surface of $\mathrm{Cu} \mathrm{NPs}$, in comparison with $\mathrm{Cu} / \mathrm{MMO}, \mathrm{PtCu}-\mathrm{NPs}$, and $\mathrm{Pt} /$ MMO samples. As shown in Fig. 3a and Supplementary Fig. 1d-g, $\mathrm{CO}$ adsorption on $\mathrm{Pt} / \mathrm{MMO}$ and $\mathrm{PtCu}-\mathrm{NPs}$ sample produces a strong and broad vibration band at $2010-2060 \mathrm{~cm}^{-1}$ and another weak band at $1810-1880 \mathrm{~cm}^{-1}$, which are ascribed to linearly bonded $\mathrm{CO}$ at $\mathrm{Pt}^{0}$ sites and bridged-adsorbed $\mathrm{CO}$ at two adjacent $\mathrm{Pt}$ atoms, respectively ${ }^{38}$. The appearance of bridge-bonded CO signifies the existence of dimer or Pt clusters, in accordance with the AC-HAADF-STEM results (Supplementary Fig. $1 \mathrm{~b}-\mathrm{c}$ and $2 \mathrm{~d}$ ). However, the relative intensity of linear and bridged band (Supplementary Fig. 1d-g) is much weaker in $\mathrm{PtCu}-\mathrm{NP}-1$ than that in $\mathrm{PtCu}-\mathrm{NP}-2$, due to the $\mathrm{Pt}$ content. The results above combining with AC-HAADF-STEM and EDS mapping images (Supplementary Figs. 1, 5 and 6) indicate $\mathrm{PtCu}-\mathrm{NP}-1$ sample consists of principal $\mathrm{PtCu}$ single atom alloy, some $\mathrm{PtCu}$ alloy and $\mathrm{Pt} / \mathrm{Cu}$ nanoclusters; while $\mathrm{PtCu}-\mathrm{NP}-2$ sample contains predominant $\mathrm{PtCu}$ alloy, some $\mathrm{Pt} / \mathrm{Cu}$ nanoclusters and a few $\mathrm{PtCu}$ single atom alloy. In contrast, neither bridged- nor linearly bonded $\mathrm{CO}$ peaks are found over PtCu-SAA (Fig. 3b). Moreover, only one asymmetric absorption band between 2060 and $2140 \mathrm{~cm}^{-1}$ is observed, indicating the overlapping signals for $\mathrm{CO}$ adsorption between the isolated Pt atoms and Cu NPs (Fig. 3b-c). To clearly distinguish the overlapping peaks, in situ CO-DRIFTS spectrum dependent on temperature were recorded on PtCu-SAA, with $\mathrm{Cu}$ / MMO as a reference sample, which were fitted and deconvoluted via multi-peaks Gaussian fitting. The whole profiles of $\mathrm{Cu} / \mathrm{MMO}$ are deconvoluted to a main peak at $2097 \mathrm{~cm}^{-1}$ and another weak peak at $2116 \mathrm{~cm}^{-1}$ (Fig. $3 \mathrm{~d}$ ), which are usually attributed to $\mathrm{CO}$ chemisorbed on $\mathrm{Cu}^{0}$ and $\mathrm{Cu}^{+}$species, respectively ${ }^{39-41}$. Interestingly, an obvious shoulder peak (Fig. 3e, f) is observed for PtCu-SAA within 2080-2090 $\mathrm{cm}^{-1}$, compared with $\mathrm{Cu} / \mathrm{MMO}$ samples at the same temperature. The whole profiles of PtCu-SAA were reasonably fitted and deconvoluted to three peaks as follows: an obvious shoulder peak centered at $2088 \mathrm{~cm}^{-1}$ and the two peaks analogous to $\mathrm{Cu} / \mathrm{MMO}$ sample with same peak position and FWHM. This unique absorption band centered at $2088 \mathrm{~cm}^{-1}$ is assigned to the linear adsorption of $\mathrm{CO}$ on isolated single $\mathrm{Pt}$ atoms ${ }^{29,42,43}$. Hence, the results of in situ CO-DRIFTS confirm that $\mathrm{Pt}$ species exists as isolated atom in PtCu-SAA samples, in agreement with the above AC-HAADF-STEM observations.

As discussed above, infrared spectroscopy and electron microscopy provide useful information about surface and structure properties, but no $\mathrm{Cu}$-containing and $\mathrm{Pt}$-containing crystal phases were detected in the XRD patterns of PtCu-SAA sample (Fig. 1a), primarily due to the insensitivity of X-ray diffraction to low content and/or small clusters. Herein, we used in situ extended X-ray absorption fine spectroscopy (EXAFS) at the Pt-L3 edge and Cu-K edge to further confirm the atomically dispersed $\mathrm{Pt}$ and to determine the coordination structure of $\mathrm{Pt}$ and $\mathrm{Cu}$. The Fourier transforms spectrum in the R space from the $k^{3}$-weighted EXAFS of $\mathrm{PtCu}-\mathrm{SAA}$ sample exhibits one prominent peak in the region $\sim 2.2-2.3 \AA$ (Fig. 4a), which is located between $\mathrm{PtO}_{2}$ standard sample and $\mathrm{Pt}$ foil, indicating the formation of $\mathrm{PtCu}$ alloy ${ }^{43}$. Supplementary Table 1 lists the fitting results including coordination numbers $(\mathrm{CN})$ and structural parameters. The Pt foil shows 12 Pt-Pt coordination at $2.77 \AA$; $\mathrm{PtO}_{2}$ displays $6 \mathrm{Pt}-\mathrm{O}$ coordination (2.05 $\AA$ ) and $6 \mathrm{Pt}-\mathrm{Pt}$ coordination $(3.09 \AA)$. Surprisingly, regarding $\mathrm{PtCu}-\mathrm{SAA}$ sample, only $7.4 \mathrm{Pt}-\mathrm{Cu}$ coordination at $2.57 \AA$ is identified; neither $\mathrm{Pt}-\mathrm{Pt}$ nor $\mathrm{Pt}-\mathrm{O}$ coordination contribution is detected. This demonstrates that predominant $\mathrm{Pt}$ are distributed as isolated and individual atom surrounded by $\mathrm{Cu}$ atoms rather than MgAl-MMO support. ${ }^{22,23}$ To further strengthen this result, the wavelet transforms (WT) analysis of Pt EXAFS oscillations was conducted, giving powerful resolution in both $k$ and $\mathrm{R}$ spaces. As illustrated by the WT contour plots of Pt foil (Fig. 4b) and $\mathrm{PtO}_{2}$ (Supplementary Fig. 7), the intensity maxima at $\sim 12 \AA^{-1}$ and $\sim 6 \AA^{-1}$ are attributed to the $\mathrm{Pt}-\mathrm{Pt}$ and $\mathrm{Pt}-\mathrm{O}$ contributions, respectively. In contrast, for the WT contour plot of PtCu-SAA (Fig. 4c), one intensity maximum at near $8 \AA^{-1}$ is exclusively observed, which is assigned to the $\mathrm{Pt}-\mathrm{Cu}$ contribution ${ }^{44}$. Therefore, the results of AC-HAADF-STEM, in situ CO-DRIFTS and in situ XAFS characterizations verify the formation of $\mathrm{PtCu}$ single atom alloy with atomically dispersed $\mathrm{Pt}$ atoms on the surface of $\mathrm{Cu}$ nanoclusters while $\mathrm{Pt}$ deposited on $\mathrm{MgAl}-\mathrm{MMO}$ support is not detected on PtCu-SAA samples.

Catalytic performance for glycerol hydrogenolysis. The catalytic properties of monometallic samples ( $\mathrm{Cu} / \mathrm{MMO}$ and $\mathrm{Pt} / \mathrm{MMO})$ and various $\mathrm{PtCu}$ alloy samples ( $\mathrm{PtCu}-\mathrm{SAA}, \mathrm{PtCu}-\mathrm{NPs}$ ) were investigated towards glycerol hydrogenolysis to 1,2-PDO. These three $\mathrm{PtCu}-\mathrm{SAA}$ samples with different $\mathrm{Pt} / \mathrm{Cu}$ ratios were synthesized to study the necessity of Pt single atom site (Supplementary Fig. 8). The initial activity shows an almost linear enhancement with the increase of Pt content from $0.10 \mathrm{wt} . \%$ (PtCu-SAA-1) to 0.15 wt.\% (PtCu-SAA-2) and then to $0.21 \mathrm{wt}$.

Table 1 Physicochemical parameters of samples.

\begin{tabular}{|c|c|c|c|c|c|c|}
\hline Samples & $\begin{array}{l}\text { BET } \\
\left(m^{2} \cdot g^{-1}\right)\end{array}$ & $\begin{array}{l}\text { Cu content }{ }^{a} \\
\text { (wt.\%) }\end{array}$ & $\begin{array}{l}\text { Pt content } \\
\text { (wt.\%) }\end{array}$ & $\begin{array}{l}\text { Mean size } \\
(\mathrm{nm})\end{array}$ & $\begin{array}{l}D_{M}{ }^{c} \\
(\%)\end{array}$ & $\begin{array}{l}\mathbf{R}_{\mathrm{Cu}}{ }^{d} \\
(\%)\end{array}$ \\
\hline PtCu-SAA & 168.4 & 3.2 & 0.21 & $2.7(\mathrm{Cu})$ & $50.7(\mathrm{Cu})$ & 88.2 \\
\hline $\mathrm{Cu} / \mathrm{MMO}$ & 153.2 & 3.3 & - & $2.9(\mathrm{Cu})$ & $52.3(\mathrm{Cu})$ & 90.8 \\
\hline
\end{tabular}

${ }^{a}$ Contents of metal $\mathrm{Cu}$ and Pt were determined by ICP-AES

bMean metal particle size of $\mathrm{Cu}$ and Pt were determined by TEM

'Dispersion of metallic $\mathrm{Cu}$ and $\mathrm{Pt}$ were measured based on $\mathrm{N}_{2} \mathrm{O}$ chemisorption and hydrogen oxygen $\left(\mathrm{H}_{2}-\mathrm{O}_{2}\right)$ titration experiments, respectively

dReduction degree of $\mathrm{Cu}$ was determined by $\mathrm{H}_{2}$-TPR measurements 

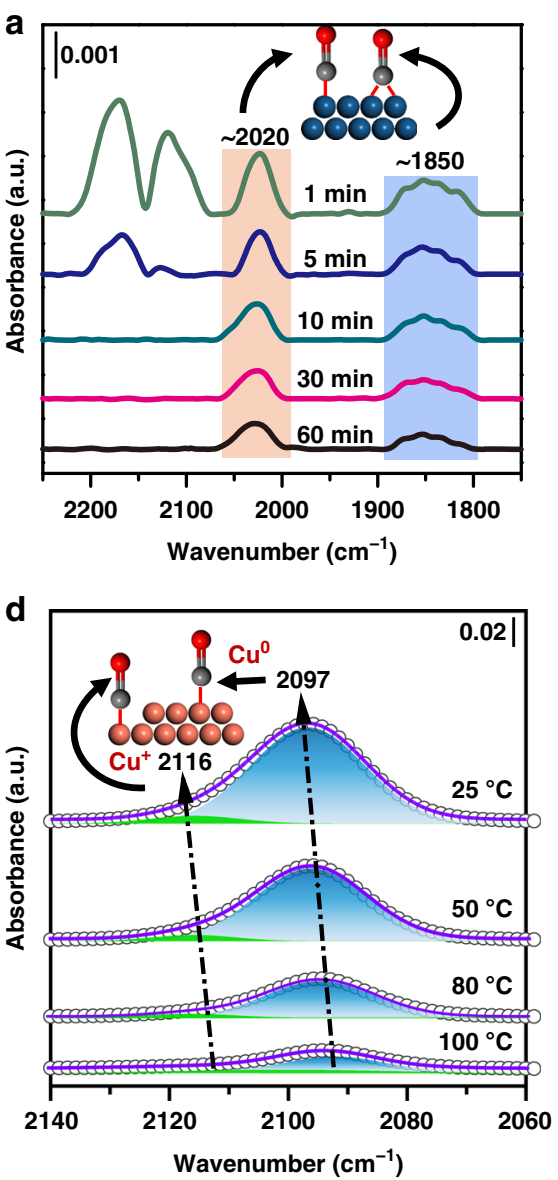
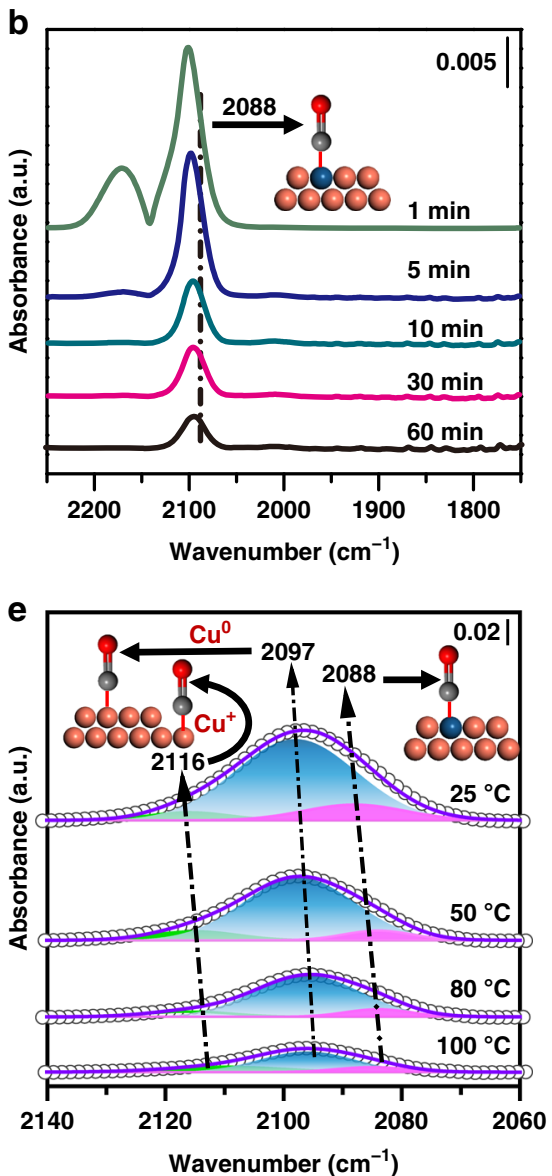
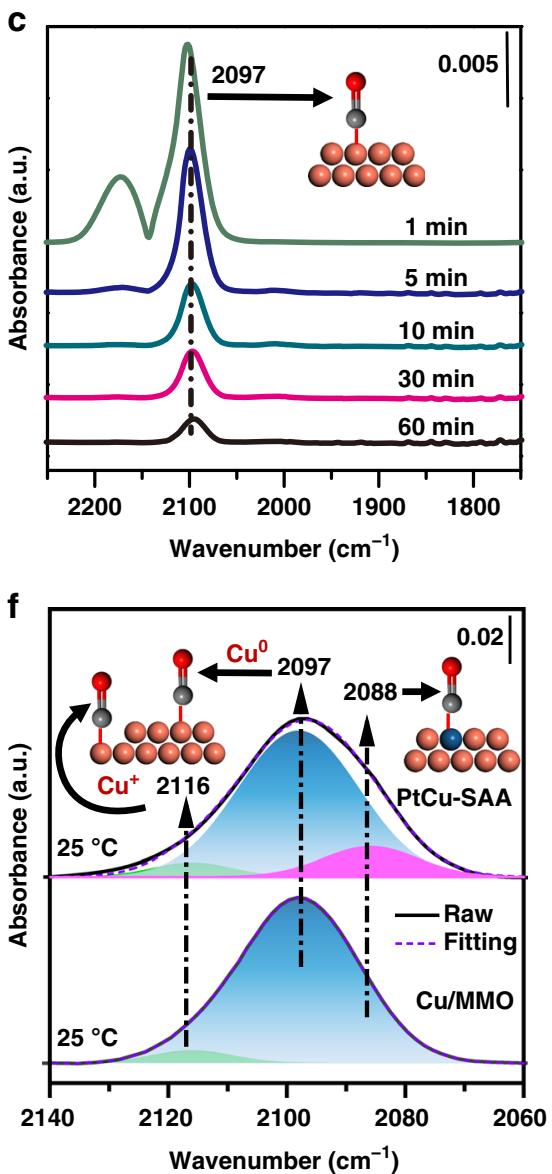

Fig. 3 In situ infrared spectroscopy studies on PtCu-SAA surface. In situ CO-DRIFTS spectra of a Pt/MMO, b PtCu-SAA, and c Cu/MMO purging with helium as a function of time; the enlarged and Gaussian fitting spectra with a fixed peak position and FWHM of $\mathbf{d} \mathrm{Cu} / \mathrm{MMO}$ and $\mathbf{e}$ PtCu-SAA as a function of temperature (the black hollow circle: experimental data; the violet solid line: fitting curve); $\mathbf{f}$ in situ CO-DRIFTS spectra of Cu/MMO and PtCu-SAA at $25^{\circ} \mathrm{C}$ (the black solid line: experimental data; the violet dotted line: fitting curve). Cu, orange, Pt, blue, $\mathrm{C}$, gray, $\mathrm{O}$, red.
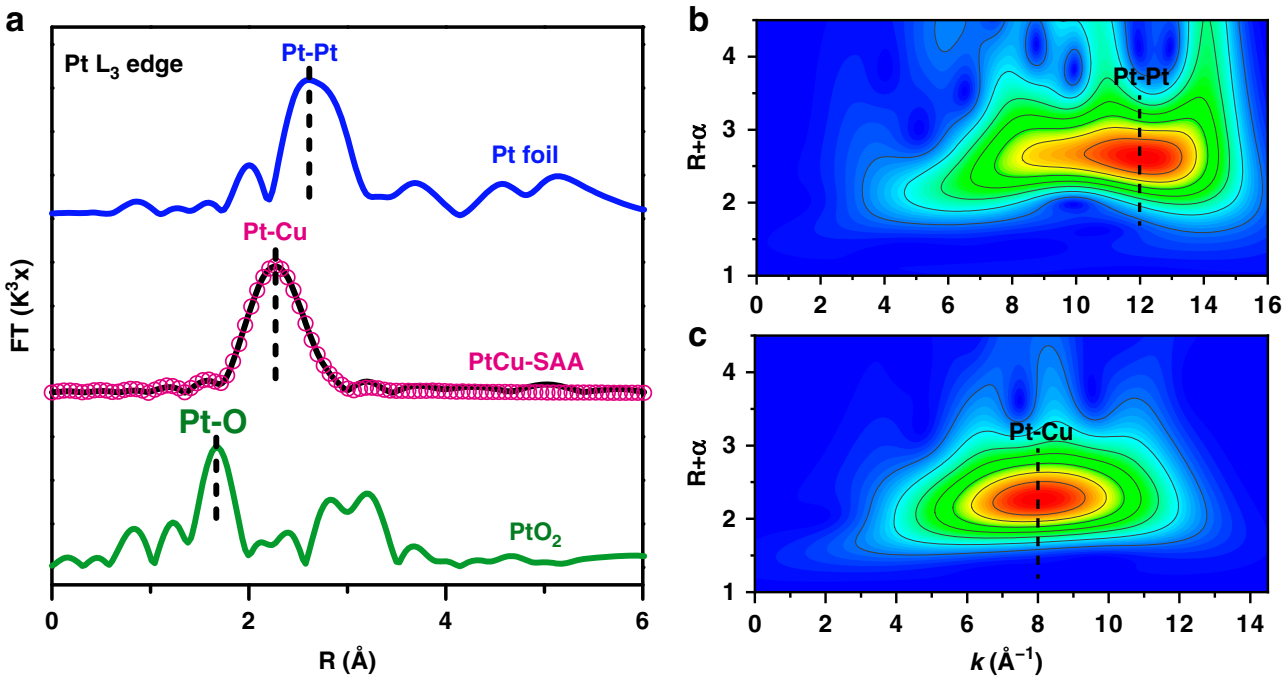

Fig. 4 Characterization and identification of PtCu single atom alloy. a In situ Pt $\mathrm{L}_{3}$-edge EXAFS Fourier-transform spectra of Pt foil, PtCu-SAA (the empty magenta circle: fitting curve; the black solid line: experimental data) and $\mathrm{PtO}_{2}$ sample, the in situ EXAFS wavelet transforms spectra of $\mathbf{b}$ Pt foil and c PtCu-SAA, respectively. 
a

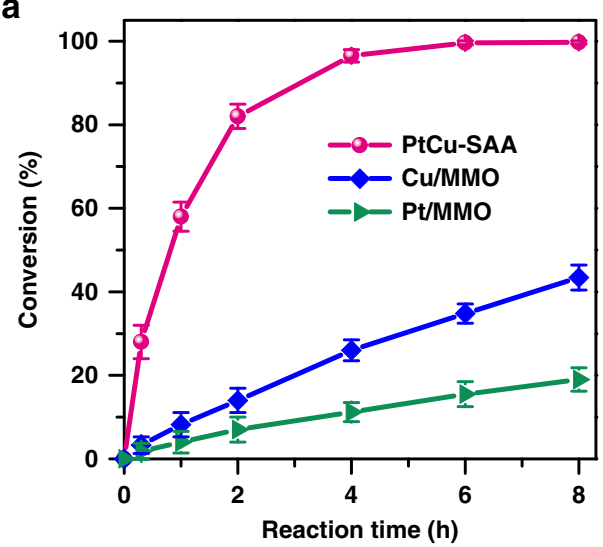

C

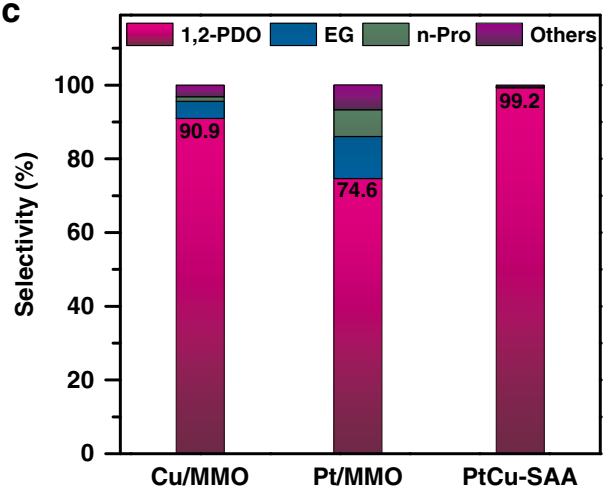

b
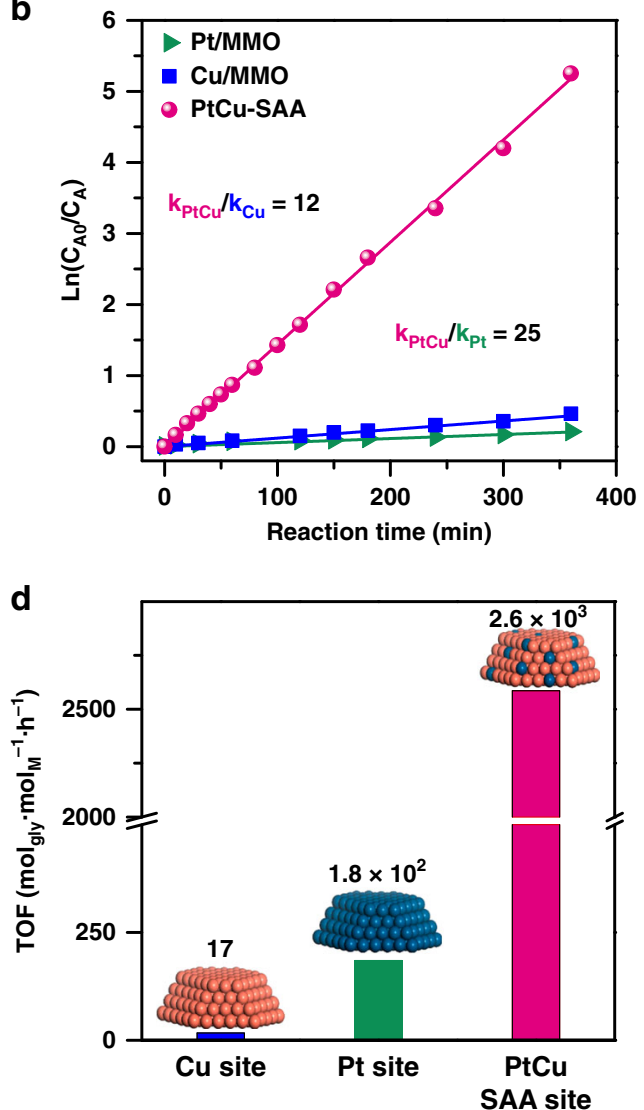

Fig. 5 Reaction studies on glycerol hydrogenolysis to 1,2-PDO. Catalytic evaluation of PtCu-SAA and monometallic catalysts (Pt/MMO and Cu/MMO) toward glycerol hydrogenolysis to 1,2-PDO: a conversion versus reaction time, $\mathbf{b}$ In $\left(C_{A O} / C_{A}\right)$ versus reaction time, $\mathbf{c}$ the product selectivity, and $\mathbf{d}$ the TOF value determined as moles of initial glycerol converted per mole of exposed active sites per hour in the catalytic dynamic range. Reaction conditions: 10 mL of glycerol alcoholic solution (10 wt. \%), $0.14 \mathrm{~g}$ of catalyst, $200^{\circ} \mathrm{C}$, and $2.0 \mathrm{MPa}$ of $\mathrm{H}_{2}$ pressure. Error bars were defined as standard deviation, $n=3$.

$\%$ (PtCu-SAA), and their selectivity maintains above 96\%. This demonstrates the single atom alloy serves as intrinsic active site. Thus, the PtCu-SAA sample was chosen as the target catalyst due to its optimal catalytic performance.

As shown in Fig. 5, both $\mathrm{Pt} / \mathrm{MMO}$ and $\mathrm{Cu} / \mathrm{MMO}$ catalysts give a low conversion (14.5\% and $38.9 \%$ ), and the 1,2-PDO selectivity reaches at a normal level (74.6\% and 90.9\%). The main by-products are ethylene glycol and $n$-propanol, resulting from the cleavage of $\mathrm{C}-\mathrm{C}$ bond and excessive hydrogenolysis, respectively. Interestingly, $\mathrm{PtCu}-\mathrm{SAA}$ sample displays significantly enhanced catalytic performance (conversion: 99.6\%; selectivity: 99.2\%). The high activity and selectivity, is superior to the previously reported bimetallic catalysts (Supplementary Table 3$)$. Even at a low temperature $\left(\sim 120^{\circ} \mathrm{C}\right)$, the $\mathrm{PtCu}-\mathrm{SAA}$ catalyst also exhibits a satisfied catalytic performance (Supplementary Table 4). However, both the conversion and selectivity (Supplementary Table 2) show a sharp decrease from 99.6\% and $99.2 \%$ (PtCu-SAA) to $89.5 \%$ and $90.4 \%$ (PtCu-NP-1), and then to $58.8 \%$ and $71.2 \%$ ( $\mathrm{PtCu}-\mathrm{NP}-2)$, respectively. This demonstrates $\mathrm{PtCu}$ single atom alloy as active sites affords higher catalytic performance than $\mathrm{PtCu}$ alloy and $\mathrm{Pt} / \mathrm{Cu}$ nanoclusters. Furthermore, the plots of $\ln \left(C_{\mathrm{A} 0} / C_{\mathrm{A}}\right)$ as a function of reaction time are straight lines starting with the origin (Fig. 5b), indicating a pseudo first-order reaction with respect to glycerol. The calculated rate constant for $\mathrm{PtCu}-\mathrm{SAA}$ is $1.4 \times 10^{-2} \mathrm{~min}^{-1}$, which is greatly larger than that for $\mathrm{Cu} / \mathrm{MMO}\left(1.2 \times 10^{-3} \mathrm{~min}^{-1}\right)$ and $\mathrm{Pt} / \mathrm{MMO}$ $\left(5.7 \times 10^{-4} \mathrm{~min}^{-1}\right)$. The results show a significantly promoted catalytic performance with the synergistic effect between $\mathrm{Cu}$ and $\mathrm{Pt}$.

To further reveal the unique intrinsic catalytic activity, the turnover frequency (TOF) was measured for glycerol hydrogenolysis to 1,2-PDO (Fig. 5d and Supplementary Table 3). The TOF value of $\mathrm{Cu} / \mathrm{MMO}$ catalyst $\left(17 \mathrm{~mol}_{\text {glycerol }} \cdot \mathrm{mol}_{\mathrm{Cu}}{ }^{-1} \cdot \mathrm{h}^{-1}\right)$ is close to that of traditional $\mathrm{Cu}$-based catalysts. The $\mathrm{Pt} / \mathrm{MMO}$ catalyst shows a good TOF value of $1.8 \times 10^{2} \mathrm{~mol}_{\text {glycerol }} \cdot \mathrm{mol}_{\mathrm{Pt}}{ }^{-1} \cdot \mathrm{h}^{-1}$ compared with other noble metal catalysts. Notably, the TOF value of $\mathrm{PtCu}-\mathrm{SAA}$ catalyst dramatically reaches up to $2.6 \times 10^{3}$ $\mathrm{mol}_{\text {glycerol }} \cdot \mathrm{mol}_{\mathrm{PtCu}-\mathrm{SAA}}{ }^{-1} \cdot \mathrm{h}^{-1}$, calculated on the basis of moles of whole single atom alloy sites (with two atoms) on the surface of $\mathrm{PtCu}-\mathrm{SAA}$, which is $\sim 150$ and 14 times larger than monometallic $\mathrm{Cu} / \mathrm{MMO}$ and $\mathrm{Pt} / \mathrm{MMO}$ catalyst, respectively. It is worth mentioning that the TOF value of PtCu-SAA, to the best of our knowledge, is the highest level among all reported metal catalysts (Supplementary Table 3 ). Moreover, the 1,2-PDO productivity over PtCu-SAA

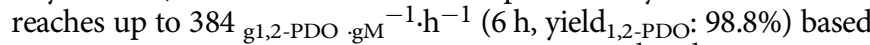
on the mass of noble metal Pt, $58.6 \mathrm{gl}, 2-\mathrm{PDO} \cdot \mathrm{gM}^{-1} \cdot \mathrm{h}^{-1}\left(2 \mathrm{~h}\right.$, yield $\mathrm{d}_{1,2}$ PDO: $81.7 \%)$ and $23.7 \mathrm{gl}, 2-\mathrm{PDO} \cdot \mathrm{gM}^{-1} \cdot \mathrm{h}^{-1}(6 \mathrm{~h}$, yield $1,2-\mathrm{PDO}: 98.8 \%)$ based overall active metal (Pt and $\mathrm{Cu}$ ) mass, which are much larger than that of reported metal catalysts under the similar conditions (Supplementary Table 3). In addition, the reusability of PtCu-SAA sample was tested by five successive hydrogenolysis recycling, giving a slight performance decrease within $4 \%$. A series of elaborate characterizations including HRTEM, AC-HAADF-STEM, EDS and in situ CO-DRIFTS study of the used catalyst don't show significant structural change compared with the fresh one (Supplementary Figs. 9-10). However, the XRD pattern of used PtCu-SAA catalyst (Supplementary Fig. 9f) displays two weak diffraction peaks centered at $2 \theta 35.5^{\circ}$ and $38.7^{\circ}$ attributed to the (111) reflection of $\mathrm{CuO}$ (JCPDS 048-1548), accounting for the slight deactivation ${ }^{45}$. In order to resolve this issue, the used catalyst 
was elaborately reduced in a hydrogen stream at $350^{\circ} \mathrm{C}$ to induce the reduction of $\mathrm{CuO}$ species, followed by another five-cycle catalytic evaluation (Supplementary Fig. 11). Surprisingly, the glycerol conversion rises to $99.2 \%$ and the 1,2-PDO selectivity goes up to $98.7 \%$ on the sixth recycle; and a slight decrease within $4 \%$ occurs during the following four cycles, demonstrating a satisfactory recyclability.

\section{Discussion}

Generally, hydrogen dissociation and spillover capacity over metal catalysts would have an important influence on catalytic performance towards hydrogenolysis reactions. The surface $\mathrm{H}_{2}$-TPR measurements after $\mathrm{N}_{2} \mathrm{O}$ pretreatment were performed to study the dissociation and spillover properties of hydrogen on the monometallic $\mathrm{Cu} / \mathrm{MMO}, \mathrm{Pt} / \mathrm{MMO}$, and bimetallic PtCu-SAA catalysts (Fig. 6a). No signal is observed for Pt/MMO sample, implying its weak interaction wtih $\mathrm{N}_{2} \mathrm{O}$. For $\mathrm{Cu} / \mathrm{MMO}$ sample, the TPR profile presents a symmetric peak at $146^{\circ} \mathrm{C}$, indicating that the surface $\mathrm{Cu}_{2} \mathrm{O}$ generated through $\mathrm{N}_{2} \mathrm{O}$ pretreatment was reduced by $\mathrm{H}_{2}$. As for $\mathrm{PtCu}-\mathrm{SAA}$ sample, only a broad asymmetrical peak emerges at the region of $106^{\circ} \mathrm{C}$, which is much lower than that of $\mathrm{Cu} / \mathrm{MMO}$ sample. This sharply decreased temperature and broader signal driven from the introduced atomically dispersed Pt can be ascribed to the enhanced hydrogen dissociation and spillover capacity, respectively ${ }^{46}$. Furthermore, the mechanism of $\mathrm{H}_{2}$ adsorption and dissociation was calculated to study the impacts of $\mathrm{PtCu}$ alloys containing isolated $\mathrm{Pt}$ atoms (Fig. 6b). For PtCu-SAA surface, chemically adsorbed $\mathrm{H}_{2}$ is present with an adsorption energy of $-0.36 \mathrm{eV}$ (magenta line), indicating $\mathrm{H}_{2}$ molecule undergoes a strong adsorption and is easy to be dissociated. As expected, it overcomes an extremely low energy barrier $(0.01 \mathrm{eV})$ to dissociate $\mathrm{H}_{2}$ into two $\mathrm{H}$ active atoms. In contrast, the hydrogen dissociation is relatively difficult on monometallic $\mathrm{Cu}$ surface (with an energy barrier of $0.39 \mathrm{eV}$, blue line) while it is barrierless on monometallic Pt surface (green line). This indicates that the hydrogen dissociation on $\mathrm{PtCu}-\mathrm{SAA}$ is between monometallic $\mathrm{Cu}$ and $\mathrm{Pt}$, which agrees with the $\mathrm{H}_{2}$-TPR results. Therefore, the potential energy barrier of hydrogen dissociation decreases significantly via introducing single $\mathrm{Pt}$ atom onto $\mathrm{Cu}$ nanoclusters, where dissociated hydrogen atoms would generate spillover from the single metal site and populate the whole $\mathrm{Cu}$ surface. This enhanced $\mathrm{H}_{2}$ dissociation ability of $\mathrm{PtCu}-\mathrm{SAA}$ provides abundant hydrogen species required for the carbonyl hydrogenation of intermediate, and thus improves its catalytic activity for hydrogenolysis of glycerol.

Although several studies have been focused on active sites and corresponding reactive pathway for glycerol hydrogenolysis to $1,2-\mathrm{PDO}$, it is still a great challenge to identify and understand intrinsic active sites of bimetallic alloy structure, owing to the complicated reaction pathway $10,33,47-49$. Herein, the promotional catalytic behavior of $\mathrm{PtCu}-\mathrm{SAA}$ was revealed via a comprehensive study including in situ glycerol-XAFS, in situ glycerol-DRIFTS experiments and DFT calculations.

In situ XAFS spectroscopy, which is sensitive for measuring the chemical states of $\mathrm{Cu}$ and $\mathrm{Pt}$, was performed to investigate their changes during the catalytic reaction. In situ $\mathrm{Cu}-\mathrm{K}$ edge XANES spectrum over fresh $\mathrm{PtCu}-\mathrm{SAA}$ shows a similar absorption edge to $\mathrm{Cu}$ foil (Fig. $7 \mathrm{a}$ ), indicating $\mathrm{Cu}^{0}$ is the main chemical state with some $\mathrm{Cu}^{+}$species, in line with the in situ CO-DRIFTS results. Once glycerol is introduced into the PtCu-SAA system, the absorption edge of $\mathrm{Cu}$ distinctly shifts to higher energy, which is close to that of $\mathrm{Cu}^{+}$in $\mathrm{Cu}_{2} \mathrm{O}$. Figure $7 \mathrm{~b}$ shows the first derivative profiles of XANES spectra with a better sense of chemical states, where the peaks at $8979.0 \mathrm{eV}$ and $8980.6 \mathrm{eV}$ are ascribed to $\mathrm{Cu}^{0}$ and $\mathrm{Cu}^{+}$, respectively. A drastic shrink occurs for the $\mathrm{Cu}^{0}$ peak after the introduction of glycerol, accompanied with a largely increased intensity of $\mathrm{Cu}^{+}$peak. This phenomenon indicates some $\mathrm{Cu}^{0}$ species undergoes oxidization to $\mathrm{Cu}^{+}$species. Moreover, the fitting results (Supplementary Table 1) of Fourier transform of $k^{3}$-weighted EXAFS spectra (Supplementary Fig. 12) show a governing $\mathrm{Cu}-\mathrm{Cu}$ coordination $(\sim 8.9)$ at $2.56 \AA$ and another weak $\mathrm{Cu}-\mathrm{O}$ coordination $(\sim 0.8)$ at $1.86 \AA$ for the fresh $\mathrm{PtCu}-\mathrm{SAA}$ catalyst. When introducing glycerol, the shell of $\mathrm{Cu}-\mathrm{Cu}$ and $\mathrm{Cu}-\mathrm{O}$ remain almost identical; however, the $\mathrm{CN}$ of $\mathrm{Cu}-\mathrm{O}$ increases to 1.6 and $\mathrm{Cu}-\mathrm{Cu}$ decreases to 4.2 , reflecting an evolution of active metal from portion of $\mathrm{Cu}^{0}$ to $\mathrm{Cu}^{+}$species ${ }^{50}$. As for the Pt-L3 edge (Fig. 7c), the white line peak displays a slight shift towards low energy compared with the fresh catalyst, suggesting $\mathrm{Pt}$ species in $\mathrm{PtCu}-\mathrm{SAA}$ is reduced to lower valence state in glycerol environment. Thus, in situ glycerol-XAFS results give an experimental evidence that glycerol molecule adsorbs and interacts with surface $\mathrm{Pt}$ and $\mathrm{Cu}$ species in $\mathrm{PtCu}-\mathrm{SAA}$.

Furthermore, we performed DFT calculations to study the nature of active sites and their binding strength to glycerol. The structural models of periodic $\mathrm{Cu}$ (111) with/without single $\mathrm{Pt}$ atom were constructed to simulate the modified/unmodified $\mathrm{Cu}$ nanoclusters, respectively. The adsorption configuration in Fig. $7 \mathrm{~d}$ shows that the $\mathrm{O} 1$ of glycerol is bound to $\mathrm{Cu}$ atom $(\mathrm{Pt}-\mathrm{Cu}$ interface site) with the $\mathrm{Cu}-\mathrm{O}$ bond length of $2.40 \AA$, and the $\mathrm{C} 2-\mathrm{H}$ undergoes adsorption on $\mathrm{Pt}$ with the formation of $\mathrm{Pt}-\mathrm{H}$ bond (bond length: $2.24 \AA$ ), in agreement with in situ glycerolXAFS results. Noticed that the adsorption structure of glycerol changes along with $\mathrm{Pt}$ addition, which display a lower glycerol adsorption energy on $\mathrm{Pt}-\mathrm{Cu}$ interface sites $(-1.02 \mathrm{eV})$ compared with $\mathrm{Cu}-\mathrm{Cu}$ sites $(-0.89 \mathrm{eV})$. As reported previously, the $\mathrm{C}-\mathrm{H}$ bond breaking plays an important role in determining the glycerol hydrogenolysis ${ }^{48}$. Hence, the formation of $\mathrm{Pt}-\mathrm{Cu}$ interface changes adsorption sites of glycerol and facilitates $\mathrm{C}-\mathrm{H}$ bond breaking, resulting in the variation of reaction pathway. Bader charge analysis reveals that electron transfer occurs from $\mathrm{H}$ atom to $\mathrm{Pt}$ and from $\mathrm{Cu}$ to $\mathrm{O}$ atom during the activation adsorption of glycerol onto PtCu-SAA surface (Supplementary Fig. 13), consistent with the in situ glycerol-XAFS results. Consequently, the $\mathrm{Pt}-\mathrm{Cu}$ interface sites of $\mathrm{PtCu}-\mathrm{SAA}$ serve as the catalytic active center that is responsible for the superior catalytic performance.

For purpose of identifying reaction intermediates of glycerol hydrogenolysis, in situ glycerol-DRIFTS measurements were conducted on $\mathrm{PtCu}-\mathrm{SAA}, \mathrm{Pt} / \mathrm{MMO}$, and $\mathrm{Cu} / \mathrm{MMO}$ catalysts. This validity was confirmed by the gas-phase glycerol hydrogenolysis reaction on $\mathrm{PtCu}-\mathrm{SAA}$ catalyst, in which catalytic performance in Supplementary Table 6 was obtained compared with previous report $^{51}$. Taking pure gaseous glycerol as reference (Fig. 8a), two strong absorption peaks centered at 1038 and $1111 \mathrm{~cm}^{-1}$ are assigned to stretching vibration $v(\mathrm{C}-\mathrm{O})$ of primary and secondary C-O bond, and another four peaks centered at 1453, 1413, 1333, and $1209 \mathrm{~cm}^{-1}$ are ascribed to $\delta\left(\mathrm{CH}_{2}\right), \delta(\mathrm{OH}), \rho(\mathrm{OH})$, and $\omega$ $\left(\mathrm{CH}_{2}\right)$, respectively ${ }^{52}$. Compared with the gaseous glycerol spectrum, two clear bands at 1746 and $1278 \mathrm{~cm}^{-1}$ are observed on Pt/ MMO and $\mathrm{Cu} / \mathrm{MMO}$ samples (Fig. 8a), which are assigned to $v$ $(\mathrm{C}=\mathrm{O})$ and $v(\mathrm{O}-\mathrm{C}-\mathrm{O})$, respectively. Theses characteristic bands are usually identified as glyceraldehyde originating from the intermediate of glycerol dehydrogenation ${ }^{53,54}$. According to experimental investigations and previous computational studies $^{4,55}$, it is concluded that glycerol undergoes dehydrogenation to glyceraldehyde as the rate-determining step followed by further dehydration and hydrogenation to 1,2-PDO.

In contrast, for $\mathrm{PtCu}-\mathrm{SAA}$ sample, two strong peaks centered at 1386 and $1688 \mathrm{~cm}^{-1}$ appear, which are ascribed to the $v\left(\mathrm{CH}_{3}\right)$ of methyl group and $v(\mathrm{C}=\mathrm{O})$ of ketone group, respectively (Fig. $8 \mathrm{a})^{52}$, rather than bending vibration of $\mathrm{H}_{2} \mathrm{O}$ molecule (Supplementary Fig. 14). As suggested previously, glycerol can 

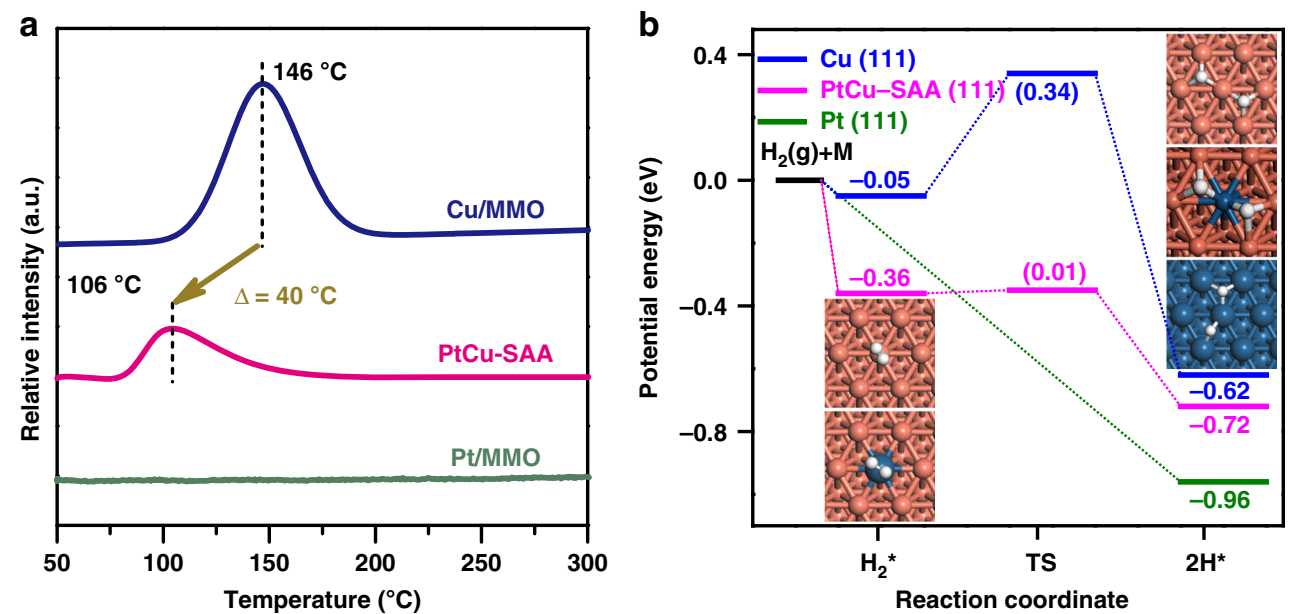

Fig. 6 Hydrogen dissociation and spillover capacity. a Surface $\mathrm{H}_{2}-\mathrm{TPR}$ spectra of various samples after $\mathrm{N}_{2} \mathrm{O}$-oxidation pretreatment: $\mathrm{Pt} / \mathrm{MMO}$, $\mathrm{PtCu}-\mathrm{SAA}$, and $\mathrm{Cu} / \mathrm{MMO}$. b Potential energies profiles for $\mathrm{H}_{2}$ dissociation pathways on the (111) facet of various samples: Pt/MMO (green line), $\mathrm{PtCu}-\mathrm{SAA}$ (magenta line) and $\mathrm{Cu} / \mathrm{MMO}$ (blue line), respectively. Numbers in the parentheses represent the reaction barriers of elementary step, and others stand for adsorption energies. $\mathrm{H}_{2}(\mathrm{~g})$ denotes gas phase of $\mathrm{H}_{2}$. $\mathrm{Cu}$, orange, $\mathrm{Pt}$, blue, $\mathrm{H}$, white.
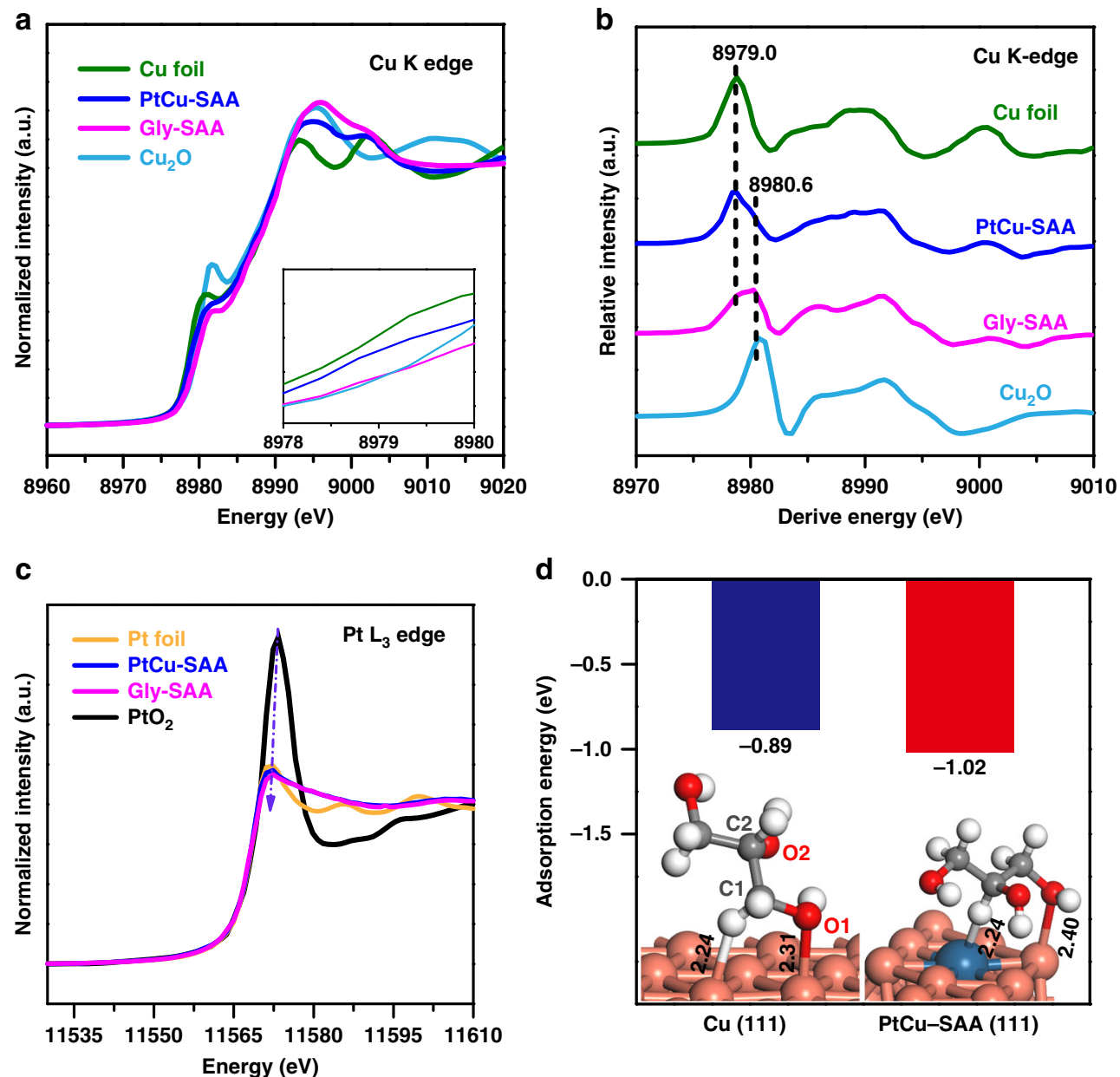

Fig. 7 Identification of catalytic active center. a In situ normalized XANES spectra and $\mathbf{b}$ corresponding first derivative profile at Cu K-edge of: Cu foil, $\mathrm{Cu}_{2} \mathrm{O}$, pristine PtCu-SAA, and PtCu-SAA exposed to glycerol (shorten for Gly-SAA). c In situ normalized XANES spectra at Pt L3-edge spectra of Pt foil, $\mathrm{PtO}_{2}, \mathrm{PtCu}-\mathrm{SAA}$, and Gly-SAA. d DFT-calculated adsorption energies of glycerol on PtCu-SAA (111) and Cu (111) facet, respectively.

convert to 2,3-dihydroxypropene via dehydration route; and the subsequent keto-enol tautomerization generates acetol, which serve as two intermediates for the production of 1,2-PDO via hydrogenation process ${ }^{48}$. Combining with in situ glycerol-XAFS and DFT calculations above, this result confirms the formation of acetol species originating from the cleavage of $\mathrm{C} 2-\mathrm{H}$ and $\mathrm{C} 1-\mathrm{O}$ in glycerol. Accordingly, glyceraldehyde and acetol, as two kinds of intermediates derived from glycerol dehydrogenation and 

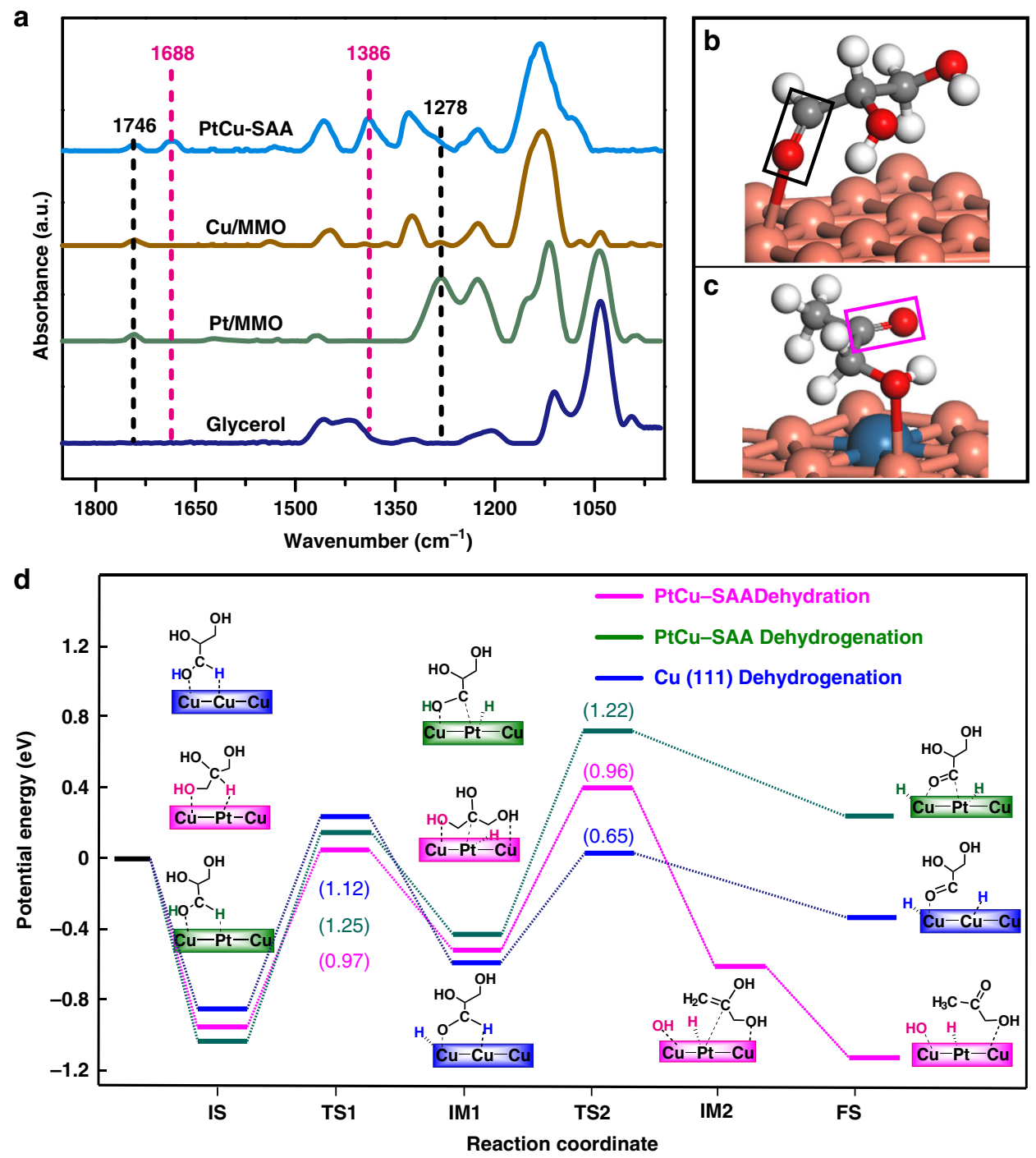

Fig. 8 Reaction pathway based on in situ experiments and DFT calculations. a In situ DRIFTS spectra of gaseous glycerol and the chemically adsorbed glycerol over Pt/MMO, Cu/MMO, and PtCu-SAA, respectively. The corresponding geometric structures for the consequent products of glycerol dissociation on b $\mathrm{Cu}$ (111) surface, and c PtCu-SAA (111) surface. Cu, orange, Pt, blue, C, grey, O, red, H, white. d Potential energy profiles for glycerol hydrogenolysis on $\mathrm{Cu}$ (111) and PtCu-SAA (111) surface. The magenta line and green line illustrates dehydration and dehydrogenation step on PtCu-SAA surface, respectively, and the blue line displays dehydrogenation step on monometallic $\mathrm{Cu}$ (111) surface. Numbers in the parentheses represent reaction barriers of elementary step.

dehydration route, can be captured on $\mathrm{Cu}-\mathrm{Cu}$ and $\mathrm{Pt}-\mathrm{Cu}$ active sites of PtCu-SAA, respectively, in contrast to the single intermediate (glyceraldehyde) detected on $\mathrm{Cu}-\mathrm{Cu}$ sites of $\mathrm{Cu} / \mathrm{MMO}$. Taking into account the same support and metal particle size between $\mathrm{PtCu}-\mathrm{SAA}$ and $\mathrm{Cu} / \mathrm{MMO}$ catalyst, the $\mathrm{Pt}-\mathrm{Cu}$ interface sites serve as the instinct active centers, in which Pt facilitates activation adsorption of hydrogen atom in secondary carbon $(\mathrm{C} 2-\mathrm{H})$ while the adjacent $\mathrm{Cu}$ accelerates activation adsorption of oxygen atom in primary carbon $(\mathrm{C} 1-\mathrm{O})$. This interfacial synergistic catalysis can change the reaction path from glycerol dehydrogenation to dehydration and therefore notably boost catalytic activity.

To provide an in-depth understanding for the reaction pathway, DFT calculations were conducted and shown in Fig. 8d. Noted that MgAl-MMO support does not show glycerol hydrogenolysis performance (Supplementary Table 5), suggesting its negligible catalytic effect. Based on the adsorption and activation of reactants, the above intermediates over $\mathrm{Cu} / \mathrm{MMO}, \mathrm{Pt} / \mathrm{MMO}$, and PtCu-SAA catalysts can be reasonably ascribed to metal active sites $(\mathrm{Pt}-\mathrm{Cu}, \mathrm{Cu}-\mathrm{Cu}, \mathrm{Pt}-\mathrm{Pt})$ rather than $\mathrm{MgAl}-\mathrm{MMO}$ support. However, these results cannot absolutely exclude the effect of support, since the PtCu-SAA was obtained via the structural transformation from hydrotalcite precursor, with a high dispersion of $\mathrm{Cu}$ nanoclusters (Table 1) and good stability (Supplementary Figs. 9-11). The resulting MgAl-MMO support contributes to the formation and loading of $\mathrm{Pt}-\mathrm{Cu}$ single atom alloy with largely enhanced catalytic efficiency of active site and satisfactory stability. Herein, three possible glycerol hydrogenolysis pathways were investigated, including the dehydration and dehydrogenation on PtCu-SAA interface site, and dehydrogenation on $\mathrm{Cu}$ (111) surface. For dehydration on PtCu-SAA interface site, the $\mathrm{H}$ of secondary carbon $(\mathrm{C} 2-\mathrm{H})$ is attacked by $\mathrm{Pt}$ site with a barrier of $0.97 \mathrm{eV}$, followed by the $\mathrm{C} 1-\mathrm{O}$ bond scission on the adjoining $\mathrm{Cu}$ site yielding a barrier of $0.96 \mathrm{eV}$. This pathway produces acetol intermediate (exothermicity: $1.26 \mathrm{eV}$ ), in which $\mathrm{C} 2-\mathrm{H}$ bond scission is the rate-determining step. 
Interestingly, Fig. 8c presents acetol intermediate derived from glycerol dehydration, whose vibration of $\mathrm{C}=\mathrm{O}$ bond coincides with that of in situ glycerol-DRIFTS spectrum (Fig. 8a). For the dehydrogenation on $\mathrm{PtCu}-\mathrm{SAA}$ interface site, $\mathrm{Pt}$ site catalyzes $\mathrm{C} 1-\mathrm{H}$ bond scission while adjacent $\mathrm{Cu}$ site facilitates the cleavage of $\mathrm{O} 1-\mathrm{H}$ bond, resulting in the formation of glyceraldehyde intermediate (endothermicity: $0.15 \mathrm{eV}$ ). By comparing the ratedetermining step of the dehydration and dehydrogenation, the energy barrier of dehydration path $(\mathrm{C} 2-\mathrm{H}$ scission, $0.97 \mathrm{eV})$ is much lower than that of dehydrogenation $(\mathrm{C} 1-\mathrm{H}$ scission, $1.25 \mathrm{eV}$ ), indicating that glycerol hydrogenolysis is prone to obey dehydration rather than dehydrogenation on $\mathrm{PtCu}-\mathrm{SAA}$ interface site. Additionally, glycerol dehydrogenation on $\mathrm{Cu}$ (111) surface was also investigated, which has been previously reported as the favorable pathway ${ }^{55}$.

As for dehydrogenation on $\mathrm{Cu}$ (111), a typical dehydrogenation process occurs on $\mathrm{Cu}$ (111) surface: the $\mathrm{O}-\mathrm{H}$ of primary carbon is attacked by one $\mathrm{Cu}$ site yielding a barrier of $1.12 \mathrm{eV}$, followed by the $\mathrm{C} 1-\mathrm{H}$ bond scission on another $\mathrm{Cu}$ site with a barrier of $0.65 \mathrm{eV}$. This path generates glyceraldehyde intermediate (exothermicity: $0.36 \mathrm{eV}$ ), whose $\mathrm{O} 1-\mathrm{H}$ scission is the rate-determining step, in agreement with the in situ glycerolDRIFTS spectrum of $\mathrm{Cu} / \mathrm{MMO}$ (Fig. 8a). Making a comparison between dehydration on $\mathrm{PtCu}-\mathrm{SAA}$ interface site and dehydrogenation on $\mathrm{Cu}$ (111), the barrier of rate-determining step in dehydration on $\mathrm{PtCu}-\mathrm{SAA}$ interface $(\mathrm{C} 2-\mathrm{H}$ scission, $0.97 \mathrm{eV})$ is lower than that of dehydrogenation on $\mathrm{Cu}(111)(\mathrm{O} 1-\mathrm{H}$ scission, $1.12 \mathrm{eV})$, suggesting that glycerol conversion on $\mathrm{PtCu}-\mathrm{SAA}$ interface site is more thermodynamically favorable than that on $\mathrm{Cu}-\mathrm{Cu}$ site. The detailed energies and corresponding geometric structures for the elementary step on different sites are listed in Supplementary Tables 7-9 and Supplementary Fig. 15. This DFT study on reaction mechanism reveals that the introduction of isolated $\mathrm{Pt}$ changes reaction pathway with enhanced catalytic reactivity from the thermodynamic point of view.

According to the experimental studies and computational investigations above, a reaction mechanism of glycerol hydrogenolysis over PtCu-SAA catalyst is proposed in Fig. 9. Firstly, glycerol molecule undergoes adsorption and activation on $\mathrm{Pt}-\mathrm{Cu}$ interface site, in which the $\mathrm{O}$ atom $(\mathrm{C}-\mathrm{O})$ binding with primary carbon adsorbs on $\mathrm{Cu}$ site and the $\mathrm{H}$ atom $(\mathrm{C}-\mathrm{H})$ at the secondary carbon adsorbs on $\mathrm{Pt}$ site. Subsequently, dehydration occurs via cleaving the adsorbed primary $\mathrm{C}-\mathrm{O}$ and second $\mathrm{C}-\mathrm{H}$ bond, leading to the formation of a 2,3-enol, followed by a further rearrangement to acetol. Finally, $\mathrm{H}$ atom combines with acetol to produce the target product 1,2-PDO. The synergistic catalysis between $\mathrm{Cu}$ and isolated $\mathrm{Pt}$, which takes the merits of unique atomic-scale surface active center, is responsible for the significantly improved activity and selectivity.

In summary, we synthesized a $\mathrm{PtCu}-\mathrm{SAA}$ by utilizing a trace amount of single $\mathrm{Pt}$ atom immobilized on $\mathrm{Cu}$ derived from an LDHs precursor. In situ CO-DRIFTS, AC-HAADF-STEM and in situ EXAFS results confirm an absolutely isolated $\mathrm{Pt}$ atoms dispersed onto the surface of $\mathrm{Cu}$ nanoclusters. This as-obtained $\mathrm{PtCu}-\mathrm{SAA}$ highlights the huge advantage of synergistic catalysis between $\mathrm{Cu}$ and $\mathrm{Pt}$, which gives a high catalytic performance and the largest TOF value towards glycerol hydrogenolysis to 1,2$\mathrm{PDO}$, in comparison with previously reported catalysts. A combination study including in situ experiments and DFT calculations validates that the $\mathrm{Pt}-\mathrm{Cu}$ interface sites serve as the active center, and the hydrogenolysis reaction follows a low barrier pathway. This interesting finding of interfacial bimetallic synergetic effect at atomic scale provides guidance for rational design and synthesis of bimetallic catalysts via an SAA approach. The method developed in this work can be extended to prepare other high-performance single atom alloy-based catalysts (especially

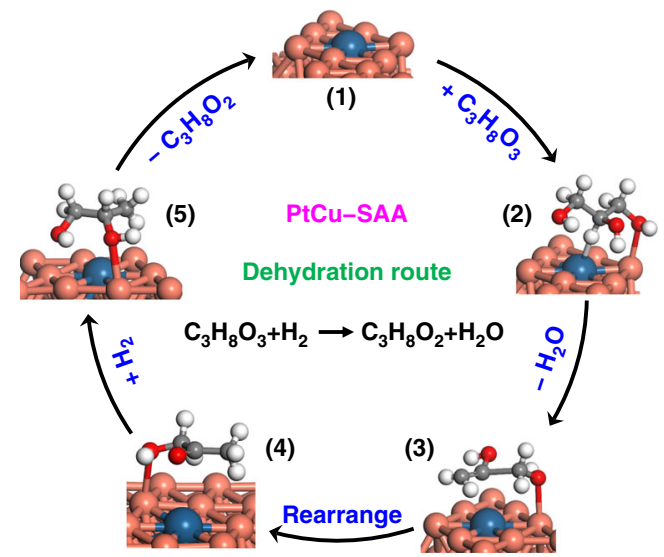

Fig. 9 Schematic representation for the reaction mechanism. Schematic illustration for the reaction mechanism of glycerol hydrogenolysis to 1,2PDO on the surface of PtCu-SAA catalyst.

noble metal-involved), with a wide range of heterogeneous catalysis applications.

\section{Methods}

Chemicals and materials. All reagents (analytical grade) were purchased from Sigma-Aldrich: $\mathrm{Mg}\left(\mathrm{NO}_{3}\right)_{2} \cdot 6 \mathrm{H}_{2} \mathrm{O}, \mathrm{Cu}\left(\mathrm{NO}_{3}\right)_{2} \cdot 3 \mathrm{H}_{2} \mathrm{O}, \mathrm{Al}\left(\mathrm{NO}_{3}\right)_{3} \cdot 9 \mathrm{H}_{2} \mathrm{O}$,

$\mathrm{H}_{2} \mathrm{PtCI}_{6} \cdot 6 \mathrm{H}_{2} \mathrm{O}$, urea, glycerol, 1,2-propanediol, 1,3-propanediol, ethylene glycol, methanol, ethanol, $n$-propanol, $n$-butanol, acetol. Deionized water was used in all experimental processes.

Synthesis of catalysts. As precursors, CuMgAl-LDH samples were prepared by a urea hydrolysis and precipitation method. In a typical procedure, a certain amount of $\mathrm{Mg}\left(\mathrm{NO}_{3}\right)_{2} \cdot 6 \mathrm{H}_{2} \mathrm{O}, \mathrm{Al}\left(\mathrm{NO}_{3}\right)_{3} \cdot 9 \mathrm{H}_{2} \mathrm{O}, \mathrm{Cu}\left(\mathrm{NO}_{3}\right)_{2} \cdot 3 \mathrm{H}_{2} \mathrm{O}$ and urea was dissolved in deionized water and sealed in a Teflon-lined stainless-steel autoclave, followed by aging at $110^{\circ} \mathrm{C}$ for $24 \mathrm{~h}$. The resulting precipitate was centrifuged, washed with deionized water and dried at $60^{\circ} \mathrm{C}$ overnight. The MgAl-LDH samples were synthesized via a similar route without $\mathrm{Cu}\left(\mathrm{NO}_{3}\right)_{2} \cdot 3 \mathrm{H}_{2} \mathrm{O}$. Afterwards, these $\mathrm{LDH}$ precursors were calcined in air atmosphere at $500{ }^{\circ} \mathrm{C}$ (heating rate: $5^{\circ} \mathrm{C} \cdot \mathrm{min}^{-1}$ ) for $4.0 \mathrm{~h}$, and then cooled down to room temperature to obtained mixed metal oxides (named as $\mathrm{MgAl}-\mathrm{MMO}$ and $\mathrm{CuMgAl}-\mathrm{MMO}$, respectively). Finally, supported $\mathrm{Cu}$ samples (named as $\mathrm{Cu} / \mathrm{MgAl}-\mathrm{MMO}$, shorten for $\mathrm{Cu} / \mathrm{MMO}$ ) were obtained via a reduction treatment of CuMgAl-MMO in a $\mathrm{H}_{2} / \mathrm{N}_{2}(1 / 9, \mathrm{v} / \mathrm{v})$ stream at $350{ }^{\circ} \mathrm{C}$ (heating rate: $2^{\circ} \mathrm{C} \cdot \mathrm{min}^{-1}$ ) for $4.0 \mathrm{~h}$. The supported PtCu SAA and NPs samples were prepared via a galvanic replacement method. In a typical process, the fresh $\mathrm{Cu}$ /MMO sample was dispersed in deionized water $(100 \mathrm{~mL})$, followed by dropwise adding desired amount of $\mathrm{H}_{2} \mathrm{PtCl}_{4}$ solution $(7.7 \mathrm{mM})$ in $\mathrm{N}_{2}$ atmosphere and an ultrasonic ice-water bath for $10 \mathrm{~min}$. The resulting slurry was centrifugated and washed with distilled water, and then dried in a vacuum oven at $60^{\circ} \mathrm{C}$ (named as $\mathrm{PtCu} / \mathrm{MgAl}-\mathrm{MMO}$, shorten for $\mathrm{PtCu}-\mathrm{SAA}$ ). The $\mathrm{Pt}-\mathrm{Cu}$ alloy samples with various $\mathrm{Pt} / \mathrm{Cu}$ atomic ratios in a wide range from 0.010 to $0.015,0.030,0.15$ and 0.50 were denoted as PtCu-SAA-1, PtCu-SAA-2, PtCu-SAA, PtCu-NP-1, and PtCu-NP-2, respectively. As a reference sample, $\mathrm{Pt} / \mathrm{MMO}$ was prepared by a traditional impregnation method, with identical Pt loading with PtCu-SAA samples.

Characterizations. The in situ XRD experiments were performed on a Rigaku XRD-6000 diffractometer using $\mathrm{Cu}$ Ka radiation $(40 \mathrm{kV}$ and $40 \mathrm{~mA}$ ), which is equipped with the sample cell connected to a gas mass flow and temperature programming device. The chemical composition of the samples was measured with inductively coupled plasma-atomic emission spectrometer (ICP-AES) on the Shimadzu ICPS-7500 device. Multipoint Brunauer-Emmett-Teller (BET) method was adopted to evaluate the total specific surface area using low-temperature $\mathrm{N}_{2}$ adsorption-desorption on a Micromeritics ASAP 2020 Instrument. Transmission electron microscopy (TEM) and high-resolution transmission electron microscopy (HRTEM) experiments were carried out using a JEOL JEM-2100 transmission electron microscope. Aberration-corrected high-angle annular dark-field scanning transmission electron microscopy (AC-HAADF-STEM) and element energy dispersive spectroscopy (EDS) mapping images were conducted on a JEOL JEM-ARM200F equipment. In situ EXAFS was performed at the beamline 1W1B of the Beijing Synchrotron Radiation Facility (BSRF), Institute of High Energy Physics (IHEP), Chinese Academy of Sciences (CAS). In situ DRIFTS was carried out on a Bruker TENSOR II equipped with an MCT narrow-band detector.

Catalytic evaluations for glycerol hydrogenolysis. Glycerol alcoholic solution $(10 \mathrm{~mL}, 10 \mathrm{wt} . \%)$ and catalyst at a certain molar ratio were carefully placed into a 
stainless-steel autoclave reactor $(50 \mathrm{~mL})$ at a constant stirring speed of $500 \mathrm{rpm}$. Afterwards, the reactor was purged with pure $\mathrm{H}_{2}(99.999 \%, 2.0 \mathrm{MPa})$ for five times, and then heated to the certain reaction temperature. After reaction, the resulting products were analyzed on a gas chromatograph (GC-2014C, Shimadzu Company).

DFT calculations. The periodic DFT calculations were implemented by the Vienna ab initio simulation package (VASP 5.4). General gradient approximation (GGA) of Perdew-Burke-Ernzerhoff (PBE) functional5 was used in all the calculations, and the Grimme's DFT-D3 method6 was added to investigate the effect of van der Waals interaction. The projector augmented wave (PAW) method was used to describe the core electrons. The energy barriers were determined by the climbing image nudged elastic band (CI-NEB) method.

\section{Data availability}

The primary data that support the plots within this paper and other finding of this study are available from the corresponding author on reasonable request.

Received: 4 July 2019; Accepted: 19 November 2019;

Published online: 20 December 2019

\section{References}

1. Besson, M., Gallezot, P. \& Pinel, C. Conversion of biomass into chemicals over metal catalysts. Chem. Rev. 114, 1827-1870 (2014).

2. Zhou, C. H., Beltramini, J. N., Fan, Y. X. \& Lu, G. Q. Chemoselective catalytic conversion of glycerol as a biorenewable source to valuable commodity chemicals. Chem. Soc. Rev. 37, 527-549 (2008).

3. Nakagawa, Y., Shinmi, Y., Koso, S. \& Tomishige, K. Direct hydrogenolysis of glycerol into 1,3-propanediol over rhenium-modified iridium catalyst. J. Catal. 272, 191-194 (2010).

4. Wang, S., Yin, K., Zhang, Y. \& Liu, H. Glycerol hydrogenolysis to propylene glycol and ethylene glycol on zirconia supported noble metal catalysts. ACS Catal. 3, 2112-2121 (2013).

5. Nakagawa, Y. \& Tomishige, K. Heterogeneous catalysis of the glycerol hydrogenolysis. Catal. Sci. Technol. 1, 179 (2011).

6. Tomishige, K., Nakagawa, Y. \& Tamura, M. Selective hydrogenolysis and hydrogenation using metal catalysts directly modified with metal oxide species. Green. Chem. 19, 2876-2924 (2017).

7. Falcone, D. D. et al. Evidence for the bifunctional nature of Pt-Re catalysts for selective glycerol hydrogenolysis. ACS Catal. 5, 5679-5695 (2015).

8. $\mathrm{Li}, \mathrm{B}$. et al. Carbon nanotube-supported RuFe bimetallic nanoparticles as efficient and robust catalysts for aqueous-phase selective hydrogenolysis of glycerol to glycols. ACS Catal. 1, 1521-1528 (2011)

9. Sun, Q., Wang, S. \& Liu, H. Selective hydrogenolysis of glycerol to propylene glycol on supported Pd catalysts: promoting effects of $\mathrm{ZnO}$ and mechanistic assessment of active PdZn alloy surfaces. ACS Catal. 7, 4265-4275 (2017).

10. Wan, W. et al. Controlling reaction pathways of selective $\mathrm{C}-\mathrm{O}$ bond cleavage of glycerol. Nat. Commun. 9, 4612 (2018).

11. $\mathrm{Hu}$, J. et al. Shape effect of $\mathrm{ZnO}$ crystals as cocatalyst in combined reforming-hydrogenolysis of glycerol. ACS Catal. 3, 2280-2287 (2013).

12. $\mathrm{Li}, \mathrm{X}$. et al. A facile strategy for confining $\mathrm{ZnPd}$ nanoparticles into a $\mathrm{ZnO} @ \mathrm{Al}_{2} \mathrm{O}_{3}$ support: a stable catalyst for glycerol hydrogenolysis. J. Catal. 337, 284-292 (2016).

13. Zhu, S. et al. Design of a highly active silver-exchanged phosphotungstic acid catalyst for glycerol esterification with acetic acid. J. Catal. 306, 155-163 (2013).

14. Yuan, Z. et al. Hydrogenolysis of glycerol over homogenously dispersed copper on solid base catalysts. Appl. Catal. B: Environ. 101, 431-440 (2011).

15. Wu, C. H. et al. Bimetallic synergy in cobalt-palladium nanocatalysts for $\mathrm{CO}$ oxidation. Nat. Catal. 2, 78-85 (2018).

16. Zheng, $\mathrm{X}$. et al. Theory-guided $\mathrm{Sn} / \mathrm{Cu}$ alloying for efficient $\mathrm{CO}_{2}$ electroreduction at low overpotentials. Nat. Catal. 2, 55-61 (2018).

17. Roy, C. et al. Impact of nanoparticle size and lattice oxygen on water oxidation on $\mathrm{NiFeO}_{x} \mathrm{H}_{y}$. Nat. Catal. 1, 820-829 (2018).

18. Giannakakis, G., Flytzani-Stephanopoulos, M. \& Sykes, E. C. H. Single-atom alloys as a reductionist approach to the rational design of heterogeneous catalysts. Acc. Chem. Res. 52, 237-247 (2019).

19. Kyriakou, G. et al. Isolated metal atom geometries as a strategy for selective heterogeneous hydrogenations. Science 335, 1209-1212 (2012).

20. Cui, X., Li, W., Ryabchuk, P., Junge, K. \& Beller, M. Bridging homogeneous and heterogeneous catalysis by heterogeneous single-metal-site catalysts. Nat. Catal. 1, 385-397 (2018).

21. Yamada, T. et al. Probing single Pt atoms in complex intermetallic $\mathrm{Al}_{13} \mathrm{Fe}_{4}$. J. Am. Chem. Soc. 140, 3838-3841 (2018).
22. Wang, L. et al. Atomic-level insights in optimizing reaction paths for hydroformylation reaction over $\mathrm{Rh} / \mathrm{CoO}$ single-atom catalyst. Nat. Commun. 7, 14036 (2016)

23. Greiner, M. T. et al. Free-atom-like $d$ states in single-atom alloy catalysts. Nat. Chem. 10, 1008-1015 (2018).

24. Zhang, L. et al. Coordination of atomic Co-Pt coupling species at carbon defects as active sites for oxygen reduction reaction. J. Am. Chem. Soc. 140, 10757-10763 (2018)

25. Sun, G. et al. Breaking the scaling relationship via thermally stable $\mathrm{Pt} / \mathrm{Cu}$ single atom alloys for catalytic dehydrogenation. Nat. Commun. 9, 4454 (2018).

26. Lucci, F. R. et al. Selective hydrogenation of 1,3-butadiene on platinumcopper alloys at the single-atom limit. Nat. Commun. 6, 8550 (2015).

27. Wrasman, C. J. et al. Synthesis of colloidal Pd/Au dilute alloy nanocrystals and their potential for selective catalytic oxidations. J. Am. Chem. Soc. 140 12930-12939 (2018).

28. Mori, K., Sano, T., Kobayashi, H. \& Yamashita, H. Surface engineering of a supported PdAg catalyst for hydrogenation of $\mathrm{CO}_{2}$ to formic acid: elucidating the active Pd atoms in alloy nanoparticles. J. Am. Chem. Soc. 140, 8902-8909 (2018).

29. Liu, J. et al. Tackling CO poisoning with single-atom alloy catalysts. J. Am. Chem. Soc. 138, 6396-6399 (2016).

30. Miura, H., Endo, K., Ogawa, R. \& Shishido, T. Supported palladium-gold alloy catalysts for efficient and selective hydrosilylation under mild conditions with isolated single palladium atoms in alloy nanoparticles as the main active site. ACS Catal. 7, 1543-1553 (2017).

31. Zhu, S. et al. Promoting effect of boron oxide on $\mathrm{Cu} / \mathrm{SiO}_{2}$ catalyst for glycerol hydrogenolysis to 1,2-propanediol. J. Catal. 303, 70-79 (2013).

32. Mitta, H., Seelam, P. K., Ojala, S., Keiski, R. L. \& Balla, P. Tuning Y-zeolite based catalyst with copper for enhanced activity and selectivity in vapor phase hydrogenolysis of glycerol to 1,2-propanediol. Appl. Catal. A Gen. 550, 308-319 (2018).

33. Gandarias, I., Arias, P. L., Requies, J., Güemez, M. B. \& Fierro, J. L. G. Hydrogenolysis of glycerol to propanediols over a Pt/ASA catalyst: the role of acid and metal sites on product selectivity and the reaction mechanism. Appl. Catal. B Environ. 97, 248-256 (2010).

34. Oberhauser, W. et al. Platinum on carbonaceous supports for glycerol hydrogenolysis: support effect. J. Catal. 325, 111-117 (2015).

35. Cui, G. et al. Low-temperature hydrogenation of dimethyl oxalate to ethylene glycol via ternary synergistic catalysis of $\mathrm{Cu}$ and acid-base sites. Appl. Catal. B Environ. 248, 394-404 (2019).

36. Cui, G., Wang, F., He, S. \& Wei, M. Catalytic performance of layered double hydroxide nanosheets toward phenol hydroxylation. RSC $A d v . \mathbf{6}$, 105406-105411 (2016).

37. Aristizábal, A. et al. Catalytic reduction of nitrates in water on Pt promoted $\mathrm{Cu}$ hydrotalcite derived catalysts: effect of the $\mathrm{Pt}-\mathrm{Cu}$ alloy formation. Appl. Catal. B Environ. 110, 58-70 (2011).

38. Qiao, B. et al. Single-atom catalysis of $\mathrm{CO}$ oxidation using $\mathrm{Pt} 1 / \mathrm{FeO}_{x}$. Nat. Chem. 3, 634-641 (2011).

39. Wu, J., Gao, G., Sun, P., Long, X. \& Li, F. Synergetic catalysis of bimetallic $\mathrm{CuCo}$ nanocomposites for selective hydrogenation of bioderived esters. ACS Catal. 7, 7890-7901 (2017).

40. Wang, Y. et al. Insight into the balancing effect of active $\mathrm{Cu}$ species for hydrogenation of carbon-oxygen bonds. ACS Catal. 5, 6200-6208 (2015).

41. Zheng, X., Lin, H., Zheng, J., Duan, X. \& Yuan, Y. Lanthanum oxide-modified $\mathrm{Cu} / \mathrm{SiO}_{2}$ as a high-performance catalyst for chemoselective hydrogenation of dimethyl oxalate to ethylene glycol. ACS Catal. 3, 2738-2749 (2013).

42. Yang, C. et al. Hydrogenolysis of methyl glycolate to ethanol over a Pt-Cu/ $\mathrm{SiO}_{2}$ single-atom alloy catalyst: a further step from cellulose to ethanol. Green. Chem. 20, 2142-2150 (2018).

43. Marcinkowski, M. D. et al. Pt/Cu single-atom alloys as coke-resistant catalysts for efficient C-H activation. Nat. Chem. 10, 325-332 (2018)

44. Zhao, D. et al. MXene $\left(\mathrm{Ti}_{3} \mathrm{C}_{2}\right)$ vacancy-confined single-atom catalyst for efficient functionalization of $\mathrm{CO}_{2}$. J. Am. Chem. Soc. 141, 4086-4093 (2019).

45. Xia, S., Yuan, Z., Wang, L., Chen, P. \& Hou, Z. Catalytic production of 1,2propanediol from glycerol in bio-ethanol solvent. Bioresour. Technol. 104, 814-817 (2012).

46. $\mathrm{Hu}, \mathrm{B}$. et al. Hydrogen spillover enabled active $\mathrm{Cu}$ sites for methanol synthesis from $\mathrm{CO}_{2}$ hydrogenation over Pd doped CuZn catalysts. J. Catal. 359, 17-26 (2018).

47. Xiao, Z. et al. Insights into the reaction pathways of glycerol hydrogenolysis over Cu-Cr catalysts. J. Mol. Catal. A Chem. 365, 24-31 (2012).

48. Auneau, F., Michel, C., Delbecq, F., Pinel, C. \& Sautet, P. Unravelling the mechanism of glycerol hydrogenolysis over rhodium catalyst through combined experimental-theoretical investigations. Chem. Eur. J. 17, 14288-14299 (2011) 
49. Gabrysch, T., Peng, B., Bunea, S., Dyker, G. \& Muhler, M. The role of metallic copper in the selective hydrodeoxygenation of glycerol to 1,2-propanediol over $\mathrm{Cu} / \mathrm{ZrO}_{2}$. Chem CatChem 10, 1344-1350 (2018).

50. Yang, H. et al. A highly stable copper-based catalyst for clarifying the catalytic roles of $\mathrm{Cu}^{0}$ and $\mathrm{Cu}^{+}$species in methanol dehydrogenation. Angew. Chem. Int. Ed. 57, 1836-1840 (2018).

51. Pandhare, N. N., Pudi, S. M., Biswas, P. \& Sinha, S. Selective hydrogenolysis of glycerol to 1,2-propanediol over highly active and stable $\mathrm{Cu} / \mathrm{MgO}$ catalyst in the vapor phase. Org. Process Res. Dev. 20, 1059-1067 (2016).

52. Foo, G. S., Wei, D., Sholl, D. S. \& Sievers, C. Role of Lewis and Brønsted acid sites in the dehydration of glycerol over niobia. ACS Catal. 4, 3180-3192 (2014).

53. Kwon, Y., Birdja, Y., Spanos, I., Rodriguez, P. \& Koper, M. T. M. Highly selective electro-oxidation of glycerol to dihydroxyacetone on platinum in the presence of bismuth. ACS Catal. 2, 759-764 (2012).

54. Garcia, A. C. et al. Strong impact of platinum surface structure on primary and secondary alcohol oxidation during electro-oxidation of glycerol. ACS Catal. 6, 4491-4500 (2016).

55. Wang, S., Zhang, Y. \& Liu, H. Selective hydrogenolysis of glycerol to propylene glycol on $\mathrm{Cu}-\mathrm{ZnO}$ composite catalysts: structural requirements and reaction mechanism. Chem. Asian J. 5, 1100-1111 (2010).

\section{Acknowledgements}

This work was supported by the National Natural Science Foundation of China (NSFC) (Nos. 21871021, 91741104, and 21521005), the National Key Research and Development Program (Grant No. 2017YFA0206804), and the Fundamental Research Funds for the Central Universities (Nos. XK1802-6 and buctylkxj01).

\section{Author contributions}

M.W., Xi Z., and G.C. conceived the idea and designed research. Xin Z., H.F., and L.C. performed the DFT calculations; Xi Z., G.C., and H.W. synthesized the catalysts and conducted the reaction tests; S.H. conducted the STEM analyses. L.Z. and B.W. performed the XAFS and infrared analysis, respectively. All the authors analyzed data and wrote the manuscript.

\section{Competing interests}

The authors declare no competing interests.

\section{Additional information}

Supplementary information is available for this paper at https://doi.org/10.1038/s41467019-13685-2.

Correspondence and requests for materials should be addressed to X.Z., L.Z., S.H. or M.W.

Peer review information Nature Communications thanks Youzhu Yuan, and the other, anonymous, reviewer(s) for their contribution to the peer review of this work.

Reprints and permission information is available at http://www.nature.com/reprints

Publisher's note Springer Nature remains neutral with regard to jurisdictional claims in published maps and institutional affiliations.

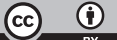

Open Access This article is licensed under a Creative Commons Attribution 4.0 International License, which permits use, sharing, adaptation, distribution and reproduction in any medium or format, as long as you give appropriate credit to the original author(s) and the source, provide a link to the Creative Commons license, and indicate if changes were made. The images or other third party material in this article are included in the article's Creative Commons license, unless indicated otherwise in a credit line to the material. If material is not included in the article's Creative Commons license and your intended use is not permitted by statutory regulation or exceeds the permitted use, you will need to obtain permission directly from the copyright holder. To view a copy of this license, visit http://creativecommons.org/ licenses/by/4.0/.

(C) The Author(s) 2019 